\title{
Application of Response Surface Methodology for Optimization of Paracetamol Particles Formation by RESS Method
}

\author{
Javad Karimi Sabet, ${ }^{1}$ Cyrus Ghotbi, ${ }^{1}$ and Farid Dorkoosh ${ }^{2}$ \\ ${ }^{1}$ Department of Chemical and Petroleum Engineering, Sharif University of Technology, P.O. Box 14395-983, Tehran, Iran \\ ${ }^{2}$ Department of Pharmaceutics, Faculty of Pharmacy, Tehran University of Medical Sciences, Tehran, Iran \\ Correspondence should be addressed to Cyrus Ghotbi, ghotbi@sharif.edu
}

Received 21 December 2011; Accepted 26 December 2011

Academic Editor: Chunyi Zhi

Copyright (C) 2012 Javad Karimi Sabet et al. This is an open access article distributed under the Creative Commons Attribution License, which permits unrestricted use, distribution, and reproduction in any medium, provided the original work is properly cited.

\begin{abstract}
Ultrafine particles of paracetamol were produced by Rapid Expansion of Supercritical Solution (RESS). The experiments were conducted to investigate the effects of extraction temperature (313-353 K), extraction pressure (10-18 MPa), preexpansion temperature (363-403 K), and postexpansion temperature (273-323 K) on particles size and morphology of paracetamol particles. The characterization of the particles was determined by Scanning Electron Microscopy (SEM), Transmission Electron Microscopy (TEM), and Liquid Chromatography/Mass Spectrometry (LC-MS) analysis. The average particle size of the original paracetamol was $20.8 \mu \mathrm{m}$, while the average particle size of paracetamol after nanonization via the RESS process was $0.46 \mu \mathrm{m}$ depending on the experimental conditions used. Moreover, the morphology of the processed particles changed to spherical and regular while the virgin particles of paracetamol were needle-shape and irregular. Response surface methodology (RSM) was used to optimize the process parameters. The extraction temperature, $347 \mathrm{~K}$; extraction pressure, $12 \mathrm{MPa}$; preexpansion temperature, $403 \mathrm{~K}$; and postexpansion temperature, $322 \mathrm{~K}$ was found to be the optimum conditions to achieve the minimum average particle size of paracetamol.
\end{abstract}

\section{Introduction}

Ultrafine materials, such as polymers, composites, ceramics, medicines, and metals, have opened new fields of application. One of the most important characteristic of ultrafine materials is that surface properties become relevant with respect to volume properties [1-7].

In the pharmaceutical industry, a large number of medicines are insoluble or poorly soluble in water. The bioavailability of these medicines is limited by their insolubility. Dissolution rate is a function of the surface area of the particles and their solubility. The surface area can be adjusted through the control of the particle size. Therefore, the bioavailability of the water insoluble drugs can be enhanced by decreasing their particle size. Besides the effect of particle size on the dissolution rate, the particle sizes have an important role in drug delivery design. Traditionally, several methods were used for producing fine particles, including milling, grinding, spray drying, and recrystallization from solution. The drawbacks of traditional micronization methods are application of high temperature and toxic solvents which can cause the degradation of the thermo-labile materials and residual toxic solvents. On the other hand, the use of traditional techniques makes it difficult to obtain particles with the desired particle size and narrow size distribution. Applications of supercritical fluids may overcome the drawbacks of conventional processes [8]. The Rapid Expansion of Supercritical Solution (RESS) is one of the supercritical fluid technologies which omit the problems of the conventional micronization methods to produce small particles with narrow particles size distribution (PSD). In the RESS process, the solute to be precipitated is initially solubilized in the supercritical solvent, usually $\mathrm{CO}_{2}$, and then the supercritical solution is expanded through a small diameter nozzle or capillary. The high supersaturation ratios and the homogeneous conditions obtained due to the rapid expansion of a supercritical solution are the unique parameters of the RESS process. High supersaturation ratios cause the formation of small particles, and 


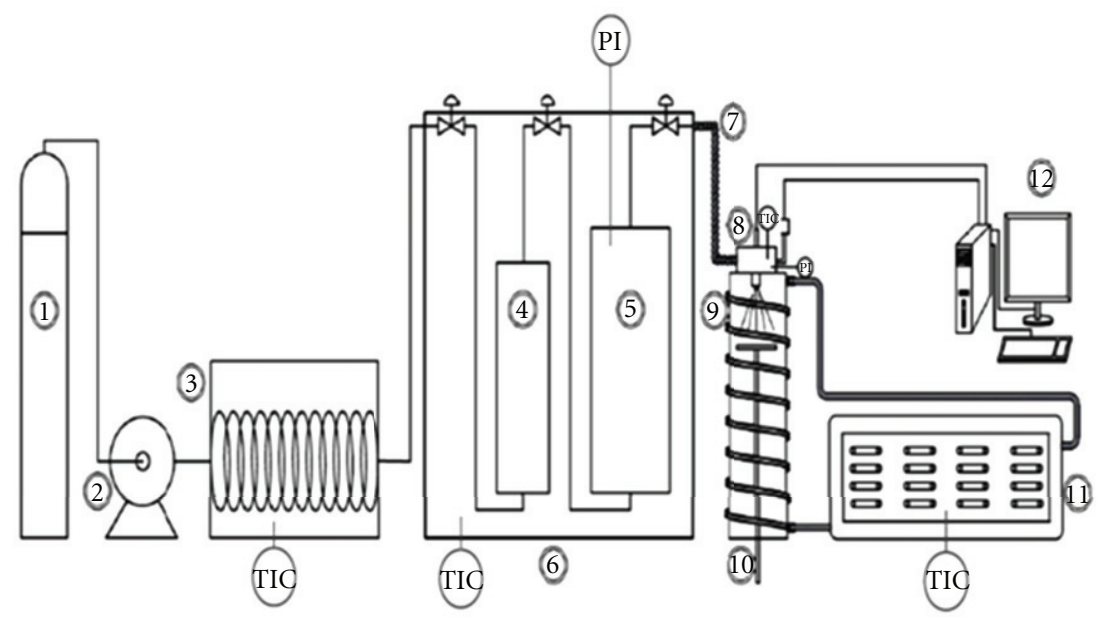

FIGURE 1: The experimental set-up for RESS process. (1) $\mathrm{CO}_{2}$ tank, (2) pump, (3) heat exchanger, $(4,5)$ equilibrium vessels, $(6)$ constanttemperature water bath, (7) preheating tube, (8) expansion device, (9) precipitation unit, (10) collection sample holder, (11) refrigerated water bath circulator, (12) data acquisition system (TI: temperature indicator; TIC: temperature indicator controller; PI: pressure indicator).

homogeneous conditions provide narrow PSD. These pa-r ameters of the RESS are used to produce very fine particles of various materials in the wide range of physical and chemical properties including organics and inorganics [9].

Paracetamol, N-acetyl-p-aminophenol, is a widely used pharmaceutical analgesic and antipyretic agent. It is used to treat conditions such as headaches, muscle aches, arthritis, backaches, toothaches, and fevers [10]. Paracetamol exhibits poor solubility in water, and its dissolution rates can be enhanced by reducing the particle size of drug to be used for injectable dosage forms, too.

In the present study, the objectives were to better understand the relationships between the influencing factors in the RESS method (extraction temperature, extraction pressure, preexpansion temperature, and postexpansion temperature) with the response (average particles size of paracetamol) and to determine optimum conditions for paracetamol nanoparticles formation from RESS process using Box-Behnken experimental design. Scanning Electron Microscopy (SEM), Transmission Electron Microscopy (TEM), and Liquid Chromatography/Mass Spectrometry (LC-MS) analysis were used for characterization of the processed and raw materials.

\section{Experimental}

2.1. Materials. Carbon dioxide with the purity of $99.99 \%$ was purchased from Farafan Gas Company, Iran. Paracetamol with the purity of $99.93 \%$ was obtained from Jalinus Company, Iran. It should be stated that all the chemicals were used as received without any further purification.

2.2. Methods. A schematic diagram of the apparatus used in this study is shown in Figure 1. The system is consisted of two sections: extraction and precipitation sections. In order to keep the temperatures of the equilibrium cells constant, a high accurate temperature-controlled water bath with an uncertainty of $\pm 0.1 \mathrm{~K}$ was used (Type WPE 45 , Memmert,
Germany). The capacity of the equilibrium cells placed in the water bath, vessels 4 and 5 in the schematic diagram, was 200 and $300 \mathrm{~cm}^{3}$, respectively. The body of the equilibrium cells, valves, and tubes were all made of stainless steel and supplied from Swagelok Company (USA). Two vessels were used in series in order to ensure achieving the equilibrium condition. The cells were filled with paracetamol at various temperature and pressure. The pressure of the cells was measured with a digital pressure transducer with an uncertainty of $\pm 0.1 \mathrm{MPa}$ (Type KM11, Ashcroft instruments, Germany). The solvent, $\mathrm{CO}_{2}$, was delivered to the system at the extraction pressure by the reciprocating pump type SFT-10 (Supercritical fluid technologies INC., USA). Sinter metal filter was used on the both ends of the vessels 4 and 5 to avoid carryover of the undissolved material with the $\mathrm{CO}_{2}$ flow. Preheating coils and the extraction vessel were immersed in the constanttemperature water bath. As shown in Figure 1, the precipitation unit consists of a precipitation cell, an expansion device and a collection device. The body of the precipitation unit is made of aluminium. The expansion device is shown in Figure 2. The main part of the expansion device is nozzle. The nozzle includes two sections, the outer body of nozzle which is made of stainless steel and has $4 \mathrm{~mm}$ length and a laser-drilled diamond section with $60 \mu \mathrm{m}$ diamter with $L / D=1$ which was located insight of the metal part. This section of the expansion device was supplied from SITEC Co. (Switzerland).

During rapid expansion, in order to avoid freezing and plugging inside the nozzle, the nozzle is heated by a cartridge heater, which is controlled by a PID controller (Type TPR2N, Han Young NUX Co., Republic of Korea). The temperature of the gas flowing through the nozzle was measured by a thermocouple (J-type) and a digital display (Type TPR-2N, Han Young NUX Co., Republic of Korea). The thermocouple was placed precisely into the solution stream approximately $7 \mathrm{~mm}$ above the entrance region of the nozzle. A high accurate temperature-controlled refrigerated water bath was used 


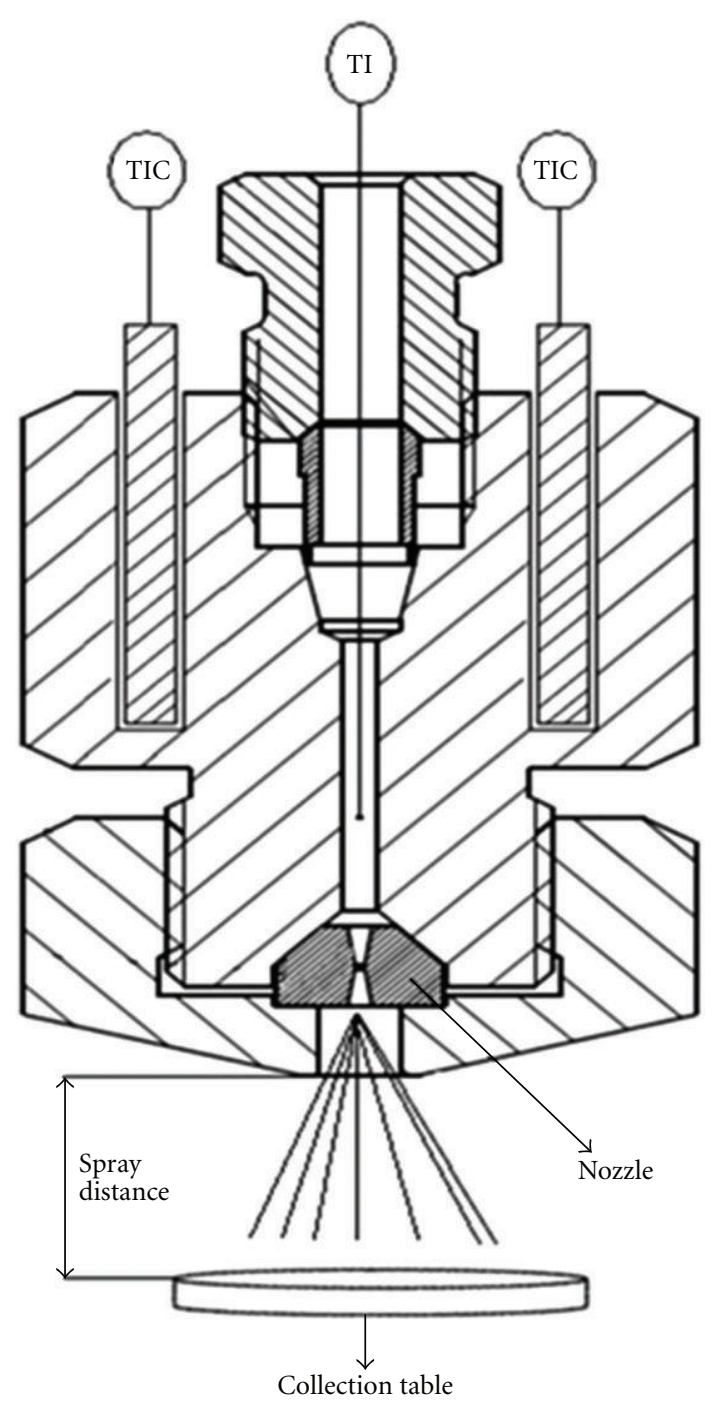

Figure 2: Heated expansion device.

to keep the temperature of the precipitation unit constant (Type WCL-P8, Daihan Scientific Co., Republic of Korea). The collection device, on which the precipitated particles are collected, is placed inside the precipitation cell. The top part of the collection device, which can be called the collection table, is made of Teflon. For collection of the particles, the glass slides are located in this table. The spray distance (the distance between the tip of the nozzle and the surface of the glass slide) can be changed via adjustable bolt and nut mechanism.

In each experiment, $2 \mathrm{~g}$ (additional material to ensure the attaining of equilibrium conditions) of paracetamol was charged into each equilibrium vessel. It is worth pointing out that glass granular beads were introduced into the equilibrium vessel in association with the chemicals to increase the contact surface area. Prior to running the experiments, air in the apparatus was purged out from the vessels and piping using $\mathrm{CO}_{2}$ injection.

\subsection{Characterization}

2.3.1. Scanning Electron Microscopy (SEM). For characterization of the size and shape of the precipitated particles, a scanning electron microscopy (SEM; Hitachi S-4160) was used. Determination of the particles size distribution was performed with the CLEMEX particles image-analysis package. The SEM figures which were taken from the collected glass slide were introduced to the image processing software. The mean particle size was computed from the average of at least 50 particles $(n>50)$, arbitrarily selected. The average diameter, da, was defined as

$$
\mathrm{da}=\frac{\left(\sum n d\right)}{\sum n} .
$$

The particle size distribution, PSD, was defined as

$$
\mathrm{PSD}=\frac{\sum n|d-\mathrm{da}|}{\sum n},
$$

where $n$ describes the number of particles of same size of $d$ and da is average particles diameter. Prior to the SEM examination the particles which were collected on the glass slide were coated with gold-palladium alloy at room temperature with sputter coater. The accelerator voltage for scanning was $15 \mathrm{kV}$.

2.3.2. Transmission Electron Microscopy (TEM). Morphology of paracetamol particles produced using the RESS process was characterized by a transmission electron microscopy (TEM; Philips CM-10). The TEM images were prepared by dispersing the paracetamol precipitates in water and drying the samples in the vacuum oven. The sample was sonicated for $5 \mathrm{~s}$ to maximize the dispersion of the aggregated particles and minimize the paracetamol solvation in water.

2.3.3. Liquid Chromatography/Mass Spectrometry (LC-MS). The unprocessed and processed paracetamol particles were analyzed by Liquid Chromatography/Mass Spectrometry (LC-MS; Agilent 6410 Series LC/MS) which has a triple quadruple detector. The particles were dissolved in methanol and injected to system directly. A $3.5 \mu \mathrm{m}-4.6 \times 100 \mathrm{~mm}$ Agilent Eclipse XDB-C18 column was used and the mobile phase was selected as methanol-water $(90: 10)$. The flow rate was $0.35 \mathrm{~mL} / \mathrm{min}$.

2.4. Experimental Design. Response surface method (RSM) is a collection of mathematical and statistical techniques that are useful for modeling and analysis in applications where a response of interest is influenced by several variables and the aim is to optimize this response. The RESS processes were affected by numerous parameters; on the other hand, overfitting occurs when a model is excessively complex, such as having too many parameters relative to the number of observations; therefore, it was necessary to select the parameters that had major effects on response. It was reported that extraction temperature, extraction pressure, preexpansion temperature, and postexpansion temperature had significant effects on average particles size [11-13]. After the identification of the important parameters, the levels of the parameters 
were identified (Table 1). Furthermore, preliminary trials were carried out in order to establish a more realistic RESS conditions. The lowest extraction pressure and extraction temperature did not provide adequate particles for analysis; the upper limit of the extraction pressure was selected according to the pump's flow rate limitation. The lowest temperature of the tubular resistance heater before the nozzle and the heater on the nozzle (preexpansion and nozzle temperature) should be kept at $363 \mathrm{~K}$. Lower temperatures cannot redress the heat loss during the expansion and caused freezing at the tip of the nozzle. The upper limit of the temperature was kept at $403 \mathrm{~K}$ in order to conduct the experiments at a temperature far away from the melting point of paracetamol $\left(T_{m}=443 \mathrm{~K}\right)$. The lowest temperature of postexpansion caused to plug the nozzle and the middle level was set at ambient temperature since the most RESS experiments perform at ambient postexpansion temperature. The levels of the independent variables were given in Table 1. The test variables, in the model equation, were coded according to $(3)$ :

$$
x_{i}=\frac{\mathbf{X}_{i}-\mathbf{X}_{0}}{\Delta \mathbf{X}}
$$

where $x_{i}$ is coded value of the independent variable, $\mathbf{X}_{i}$ is the actual value of the independent variable, $\mathbf{X}_{0}$ is the actual value of the $\mathbf{X}_{i}$ on the center point, and $\Delta \mathbf{X}$ is the step change value. The behavior of the system was by the following second-order polynomial (4):

$$
Y=A_{0}+\sum_{i=1}^{4} A_{i} x_{i}+\sum_{i=1}^{4} A_{i i} x_{i}^{2}+\sum_{i=1}^{3} \sum_{i=j+1}^{4} A_{i j} x_{i} x_{j}+\epsilon,
$$

where $Y$ is the predicted response (average particle diameter), and (4) becomes for four independent variables:

$$
\begin{aligned}
Y= & A_{0}+A_{1} x_{1}+A_{2} x_{2}+A_{3} x_{3}+A_{4} x_{4} \\
& +A_{11} x_{1}^{2}+A_{22} x_{2}^{2}+A_{33} x_{3}^{2}+A_{44} x_{4}^{2} \\
& +A_{12} x_{1} x_{2}+A_{13} x_{1} x_{3}+A_{14} x_{1} x_{4} \\
& +A_{23} x_{2} x_{3}+A_{24} x_{2} x_{4}+A_{34} x_{3} x_{4}+\epsilon,
\end{aligned}
$$

where $x_{1}, x_{2}, x_{3}$, and $x_{4}$ are input variables; $A_{0}$ is a constant; $A_{1}, A_{2}, A_{3}$, and $A_{4}$ are linear coefficients; $A_{11}, A_{22}, A_{33}$, and $A_{44}$ are quadratic coefficients; $A_{12}, A_{13}, A_{14}, A_{23}, A_{24}$, and $A_{34}$ are interaction; $\epsilon$ is noise or error.

In this study, A Box-Behnken statistical design with four factors and three levels was employed to fit secondorder polynomial model which indicated that twenty-five experiments were required for this procedure (Table 2). The Design-Expert software (version 8.0.3, Stat-Ease Inc., Minneapolis, USA) was used for model regression, plotted figures, and optimization. The $P$ values of less than 0.05 were considered to be statistically significant.

\section{Results and Discussion}

Twenty-five experiments were performed to investigate the effects of the extraction temperature, extraction pressure,
Table 1: Variables in Box-Behnken design.

\begin{tabular}{lcccc}
\hline \multirow{2}{*}{ Independent variable } & & \multicolumn{4}{c}{ Levels used } \\
& Coded symbol & -1 & 0 & 1 \\
\hline Extraction temperature (K) & $x_{1}$ & 313 & 333 & 353 \\
Extraction pressure (MPa) & $x_{2}$ & 10 & 14 & 18 \\
Preexpansion temperature (K) & $x_{3}$ & 363 & 383 & 403 \\
Postexpansion temperature (K) & $x_{4}$ & 273 & 298 & 323 \\
\hline
\end{tabular}

preexpansion temperature, postexpansion temperature, and their interactions on the size of the paracetamol particles obtained from the RESS process. All the results are shown in Table 2. It shoud be stated that all experiments were done at the spray distance, $90 \mathrm{~mm}$; nozzle diameters, $60 \mu \mathrm{m}$; and the collection time, 10 minutes unless otherwise is indicated accordingly.

The average particle size of the original paracetamol particles was $20.8 \mu \mathrm{m}$ (Figure 3). Also, the original material had a definite needle shape, whereas the processed particles had spherical shapes. SEM images, shown in Figure 4, depict the significance of size reduction of the particles processed by RESS. Depending on various experimental conditions, the average particle size of RESS produced was $0.46 \mu \mathrm{m}$. The PSD of particles obtained from runs 1, 6, 12, 13, 21, and 22 and the PSD of unprocessed particles are presented in Figures 5 and 3(b), respectively. Figure 3(b) shows that there was no original particle smaller than $6.9 \mu \mathrm{m}$.

The SEM images were obtained without any additionally preparations such as ultrasonication. However, the TEM image (Figure 6) was taken after 5 seconds of ultrasonication. Water was chosen as the dispersion medium, since paracetamol is poorly soluble in water. The samples were subject to the ultrasonication in water for 5 seconds, which was found to be optimal sonication time for paracetamol particles in water. TEM images showed that less than 5-second sonication did not provide enough dispersion, and after 5 seconds, paracetamol particles started to dissolve in water.

There is a little information about the high-pressure phase behavior of paracetamol- $\mathrm{CO}_{2}$ system. The solubility of paracetamol in pure $\mathrm{CO}_{2}$ under mild conditions (313-343 K and $10-25 \mathrm{MPa})$ is reported within $(0.66-9.66) \times 10^{-6}$ mole fraction $[14,15]$.

3.1. Mathematical Model and Optimization of RESS Conditions. Response surface optimization is more advantageous than the traditional single parameter optimization as it saves time, space, and raw material. According to the method of Box-Behnken design (BBD), the effect of extraction temperature $\left(x_{1}\right)$, extraction pressure $\left(x_{2}\right)$, preexpansion temperature $\left(x_{3}\right)$, and postexpansion temperature $\left(x_{4}\right)$ on particle size of paracetamol was studied. The application of $\mathrm{BBD}$ generated the regression equation (6), which represents an empirical relationship between the response and the tested variables (in coded units):

$$
\begin{aligned}
Y= & 0.5-0.1 x_{1}+0.099 x_{2}-0.035 x_{3}-0.28 x_{4} \\
& -0.1 x_{1} x_{2}-0.029 x_{1} x_{3}+0.007 x_{1} x_{4}-0.077 x_{2} x_{3}
\end{aligned}
$$


TABLE 2: Box-Behnken experimental design with the observed response.

\begin{tabular}{|c|c|c|c|c|c|c|c|c|c|}
\hline Run & $x_{1}$ & $x_{2}$ & $x_{3}$ & $x_{4}$ & $\begin{array}{c}\text { Extraction } \\
\text { temperature }(\mathrm{K})\end{array}$ & $\begin{array}{c}\text { Extraction } \\
\text { pressure } \\
(\mathrm{MPa})\end{array}$ & $\begin{array}{l}\text { Preexpansion } \\
\text { temperature }(\mathrm{K})\end{array}$ & $\begin{array}{l}\text { Postexpansion } \\
\text { temperature }(\mathrm{K})\end{array}$ & $\begin{array}{c}\text { Average } \\
\text { particle } \\
\text { size }(\mu \mathrm{m})\end{array}$ \\
\hline 1 & 0 & 1 & 0 & 1 & 333 & 18 & 383 & 323 & 0.136 \\
\hline 2 & -1 & 0 & 0 & 1 & 313 & 14 & 383 & 323 & 0.301 \\
\hline 3 & 1 & -1 & 0 & 0 & 353 & 10 & 383 & 298 & 0.164 \\
\hline 4 & 0 & 1 & 1 & 0 & 333 & 18 & 403 & 298 & 0.407 \\
\hline 5 & 0 & -1 & 0 & 1 & 333 & 10 & 383 & 323 & 0.236 \\
\hline 6 & 0 & 1 & 0 & -1 & 333 & 18 & 383 & 273 & 0.663 \\
\hline 7 & 0 & 1 & -1 & 0 & 333 & 18 & 363 & 298 & 0.748 \\
\hline 8 & -1 & 0 & 1 & 0 & 313 & 14 & 403 & 298 & 0.588 \\
\hline 9 & 0 & -1 & -1 & 0 & 333 & 10 & 363 & 298 & 0.25 \\
\hline 10 & 0 & -1 & 0 & -1 & 333 & 10 & 383 & 273 & 0.745 \\
\hline 11 & -1 & 0 & 0 & -1 & 313 & 14 & 383 & 273 & 0.867 \\
\hline 12 & -1 & -1 & 0 & 0 & 313 & 10 & 383 & 298 & 0.307 \\
\hline 13 & 0 & 0 & -1 & 1 & 333 & 14 & 363 & 323 & 0.231 \\
\hline 14 & -1 & 1 & 0 & 0 & 313 & 18 & 383 & 298 & 0.855 \\
\hline 15 & 1 & 0 & 1 & 0 & 353 & 14 & 403 & 298 & 0.417 \\
\hline 16 & 0 & 0 & 0 & 0 & 333 & 14 & 383 & 298 & 0.496 \\
\hline 17 & 0 & -1 & 1 & 0 & 333 & 10 & 403 & 298 & 0.218 \\
\hline 18 & 1 & 0 & 0 & 1 & 353 & 14 & 383 & 323 & 0.147 \\
\hline 19 & -1 & 0 & -1 & 0 & 313 & 14 & 363 & 298 & 0.503 \\
\hline 20 & 1 & 1 & 0 & 0 & 353 & 18 & 383 & 298 & 0.305 \\
\hline 21 & 0 & 0 & 1 & 1 & 333 & 14 & 403 & 323 & 0.187 \\
\hline 22 & 1 & 0 & 0 & -1 & 353 & 14 & 383 & 273 & 0.685 \\
\hline 23 & 1 & 0 & -1 & 0 & 353 & 14 & 363 & 298 & 0.45 \\
\hline 24 & 0 & 0 & 1 & -1 & 333 & 14 & 403 & 273 & 0.777 \\
\hline 25 & 0 & 0 & -1 & -1 & 333 & 14 & 363 & 273 & 0.827 \\
\hline
\end{tabular}

$$
\begin{aligned}
& -0.0045 x_{2} x_{4}+0.0015 x_{3} x_{4}-0.00829 x_{1}^{2} \\
& -0.078 x_{2}^{2}-0.00654 x_{3}^{2}+0.018 x_{4}^{2}
\end{aligned}
$$

where $Y$ is the response, that is, average particle size of paracetamol and $x_{1}, x_{2}, x_{3}$, and $x_{4}$ are coded values of the test values. The analysis of variance (ANOVA) was given in Table 3. The significance of each coefficient was determined by $P$ value. $P$ value less than 0.05 indicates that model terms are significant. The Model $P$ value of 0.007 implies that the model is significant. Extraction temperature $\left(x_{1}\right)$, extraction pressure $\left(x_{2}\right)$, and postexpansion temperature $\left(x_{4}\right)$ are significant model terms. Other coefficients are found to be insignificant. The coefficient of determination $\left(R^{2}\right)$ and the coefficient of adjusted determination $\left(R_{\mathrm{adj}}^{2}\right)$ of the model were 0.8763 and 0.7030 , respectively. It was determined that the model was acceptable and $R^{2}$ and $R_{\text {adj }}^{2}$ indicated the goodness of the fit with the experimental data. It should be stated that all the following figures were plotted using Design-Expert version 8.0.3 software, and in all the presented figures, the other factor was kept at level zero (medium level).

\subsection{The Main Effect of Independent Variable on the Response}

3.2.1. Effect of Extraction Temperature. The result of ANOVA (Table 3 ) indicated that extraction temperature is one of the important factors affecting the particle size of paracetamol $(P$ value $<0.05)$. Figure $7(a)$ shows the effect of extraction temperate on the average particle size. Increasing in extraction temperature caused a decrease of average particles size as seen from Figure 7(a). This could be explained as follows: by increasing the extraction temperature which leads to reduce the density of $\mathrm{CO}_{2}$ and simultaneous increase in the solutes vapour pressure. In addition, reduction in the solvent density causes a decrease in the solvent power. On the other hand, increase in the solutes vapour pressure leads to an increase in the paracetamol solubility. At higher pressures (higher than $\approx 13 \mathrm{MPa}$ ), the increase in solute vapor pressure is more significant than the decrease in $\mathrm{CO}_{2}$ density; therefore, the total effect of the two opposing phenomena increases the solubility of paracetamol in the supercritical fluid [14, 15]. Therefore, high extraction temperature induces high paracetamol solubility at a constant extraction pressure. An increase of extraction temperature from 313 to $353 \mathrm{~K}$ leads 


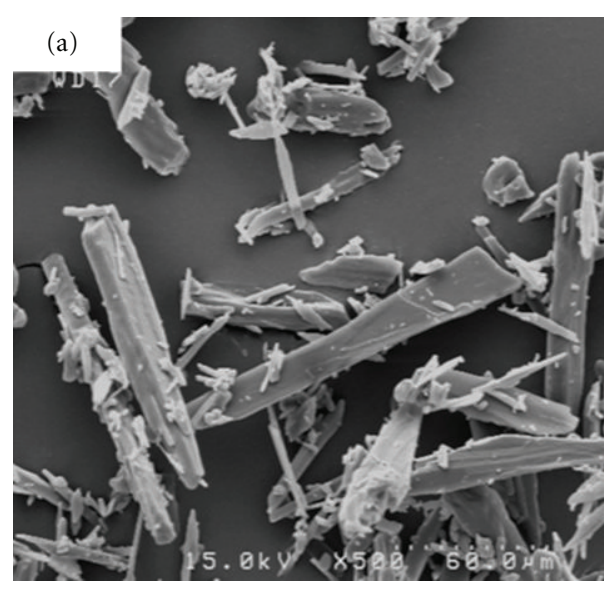

(a)

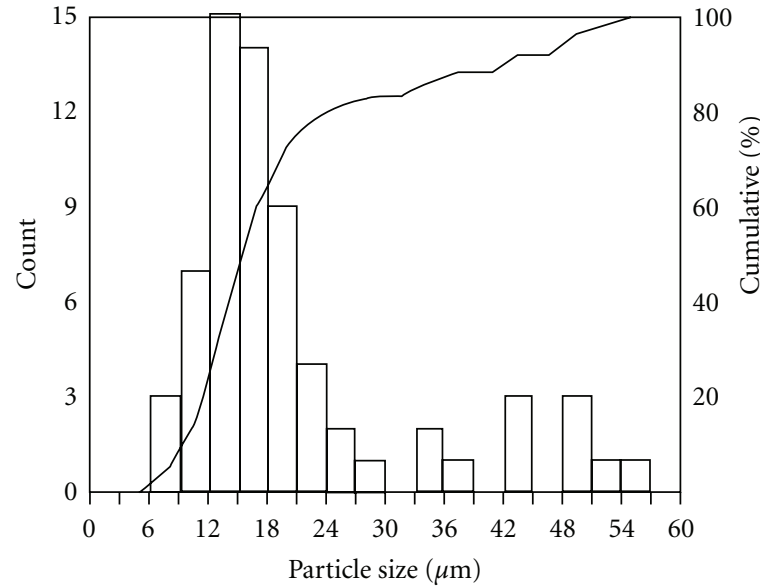

(b)

FIGURE 3: (a) The SEM images of unprocessed paracetamol particles; (b) the particle size distribution of original paracetamol.

TABLE 3: Analysis of variance (ANOVA) for response surface quadratic model.

\begin{tabular}{|c|c|c|c|c|c|c|}
\hline Source & Sum of squares & Degree of freedom & Mean square & $F$ value & $P$ value & Significant \\
\hline Model & 1.297052 & 14 & 0.0926 & 5.0579 & 0.0070 & $* *$ \\
\hline$x_{1}$ & 0.130834 & 1 & 0.1308 & 7.1427 & 0.0234 & $*$ \\
\hline$x_{2}$ & 0.118803 & 1 & 0.1188 & 6.4859 & 0.0290 & $*$ \\
\hline$x_{3}$ & 0.014352 & 1 & 0.0144 & 0.7835 & 0.3968 & NOS \\
\hline$x_{4}$ & 0.921856 & 1 & 0.9219 & 50.3273 & $<0.0001$ & $* * *$ \\
\hline$x_{1} x_{2}$ & 0.041412 & 1 & 0.0414 & 2.2608 & 0.1636 & NOS \\
\hline$x_{1} x_{3}$ & 0.003481 & 1 & 0.0035 & 0.1900 & 0.6721 & NOS \\
\hline$x_{1} x_{4}$ & 0.000196 & 1 & 0.0002 & 0.0107 & 0.9197 & NOS \\
\hline$x_{2} x_{3}$ & 0.023870 & 1 & 0.0239 & 1.3032 & 0.2802 & NOS \\
\hline$x_{2} x_{4}$ & 0.000081 & 1 & 0.0001 & 0.0044 & 0.9483 & NOS \\
\hline$x_{3} x_{4}$ & 0.000009 & 1 & 0.0000 & 0.0005 & 0.9828 & NOS \\
\hline$x_{1}^{2}$ & 0.000194 & 1 & 0.0002 & 0.0106 & 0.9200 & NOS \\
\hline$x_{2}^{2}$ & 0.017032 & 1 & 0.0170 & 0.9298 & 0.3576 & NOS \\
\hline$x_{3}^{2}$ & 0.000121 & 1 & 0.0001 & 0.0066 & 0.9369 & NOS \\
\hline$x_{4}^{2}$ & 0.000949 & 1 & 0.0009 & 0.0518 & 0.8245 & NOS \\
\hline Residual & 0.183172 & 10 & 0.0183 & & & \\
\hline Cor. total & 1.480224 & 24 & & & & \\
\hline
\end{tabular}

${ }^{*}$ Significant at $P<0.05 ;{ }^{* *}$ Significant at $P<0.01 ;{ }^{* *}$ Significant at $P<0.001$; NOS, not significant.

to increase in the supersaturation as a result of increased paracetamol concentration. According to classical nucleation theory, the increase of supersaturation leads to decrease in critical nucleus size and therefore the smaller particle was obtained [6-17]. Huang et al. [18] reported the similar result for aspirin.

3.2.2. Effect of Preexpansion Temperature. As shown in Table 3, the result of ANOVA denoted that preextraction temperature has insignificant effect on the average particle size $(P$ value $>0.05)$. It was observed from Figure $7(b)$ that increasing in preextraction temperature caused a very small decrease of the average particle size.
Huang et al. [18] have found the same result for aspirin. The authors reported that preexpansion temperature has a little effect on particle size of aspirin. However, Reverchon et al. [19], Liu and Nagahama [20], Helfgen et al. [21], and Wang et al. [22] obtain an increase in preexpansion temperature caused to increase on particles size for salicylic acid, naphthalene, benzoic acid, and titanocene dichloride, respectively. Therefore, the effect of preexpansion temperature on the particle size may be depending on the type of compounds and solute-solvent interactions at process conditions.

3.2.3. Effect of Post Expansion Temperature. From Table 3 it can be observed that the post-extraction temperature has 


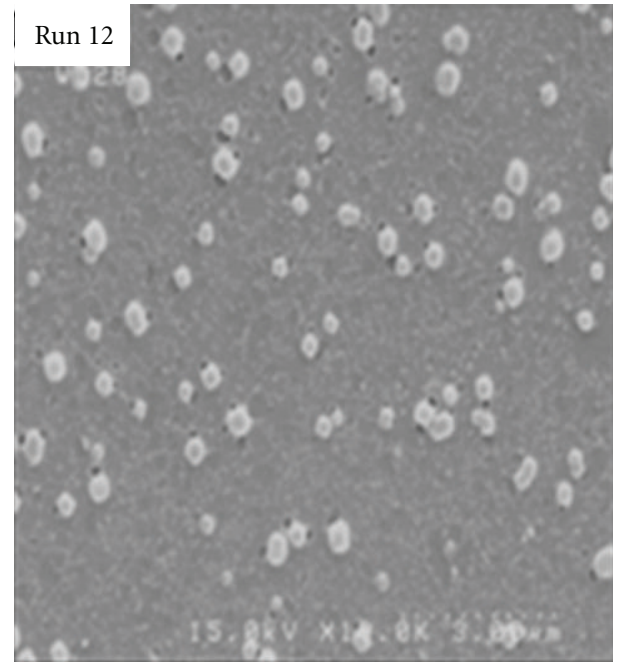

(a)

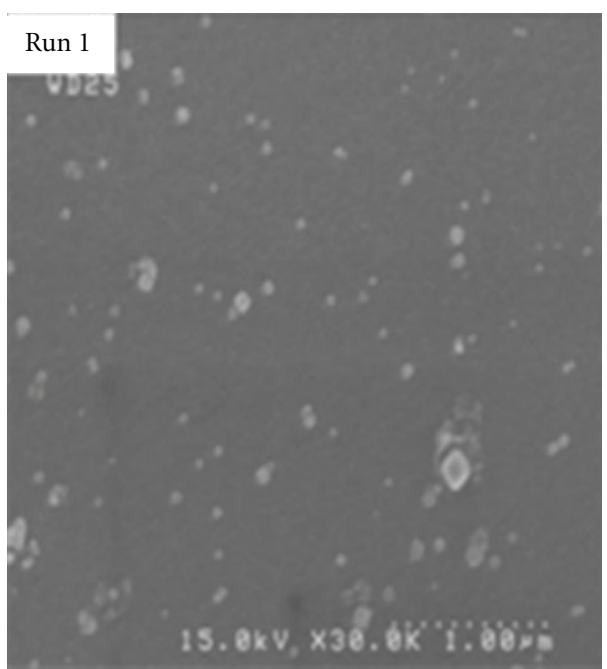

(c)

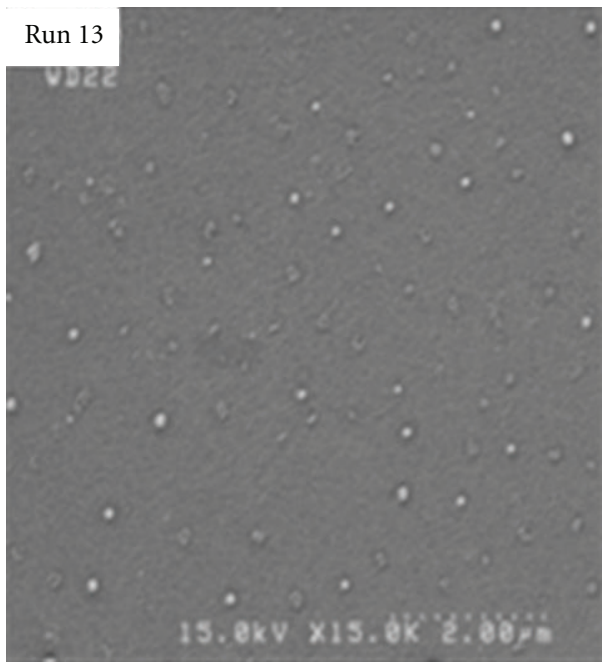

(e)

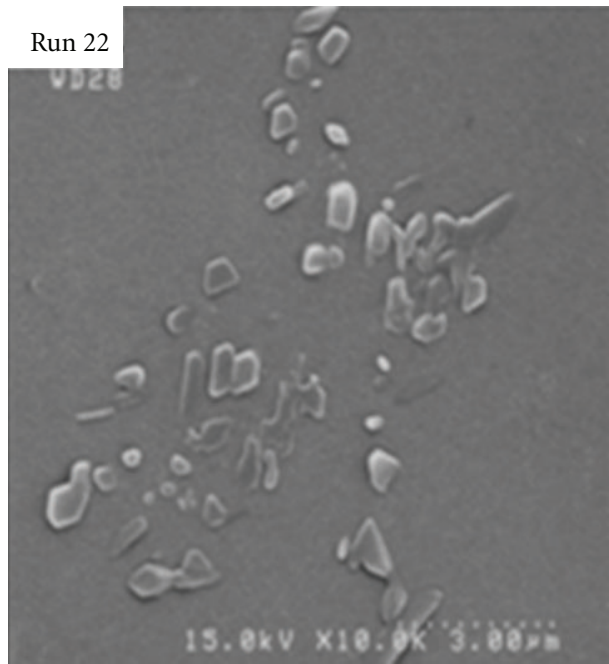

(b)

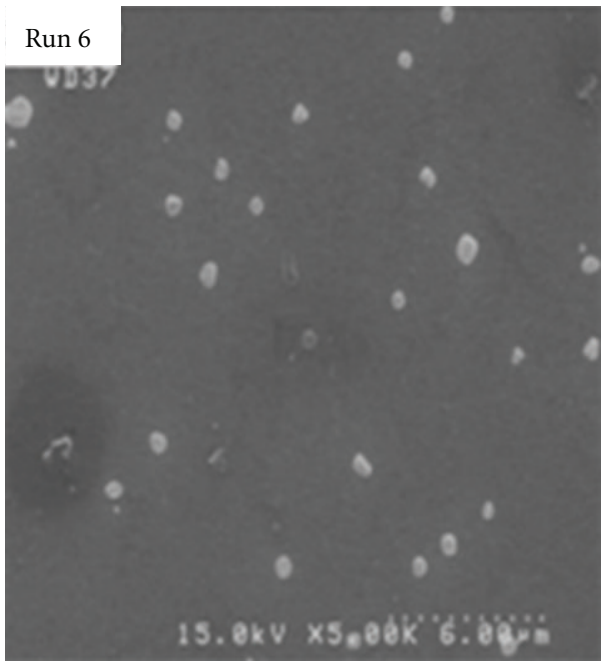

(d)

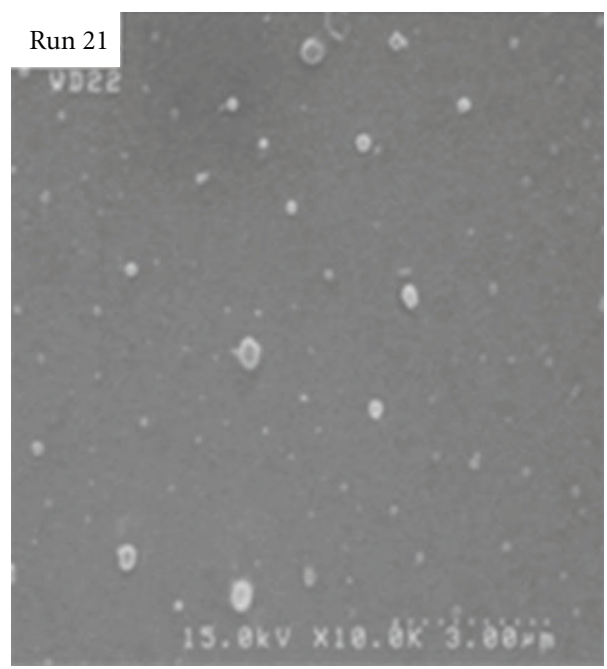

(f)

FIGURE 4: The SEM image of the processed particles obtained from different conditions. 


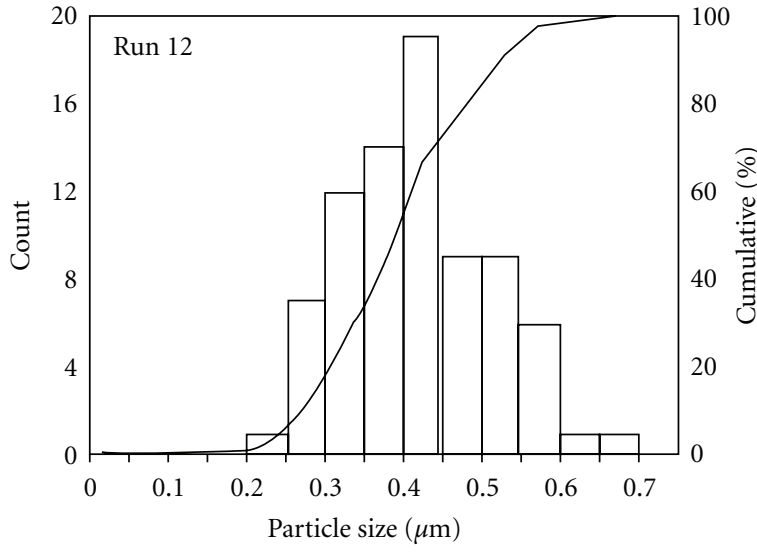

(a)

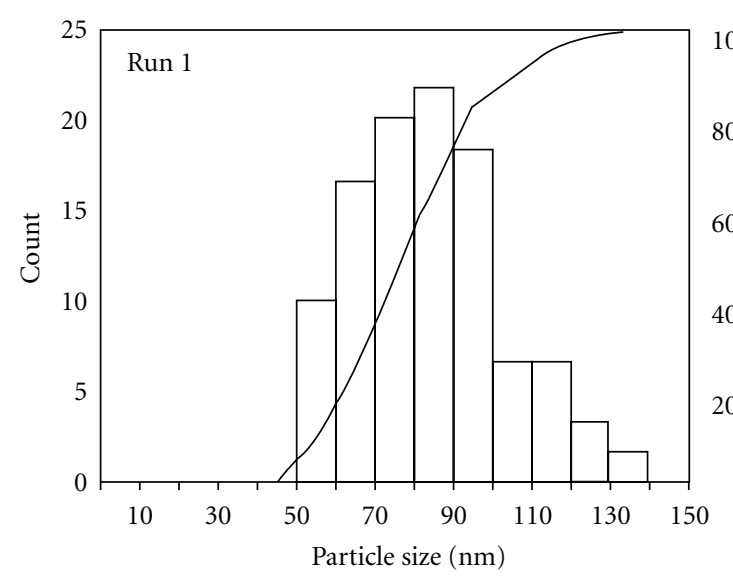

(c)

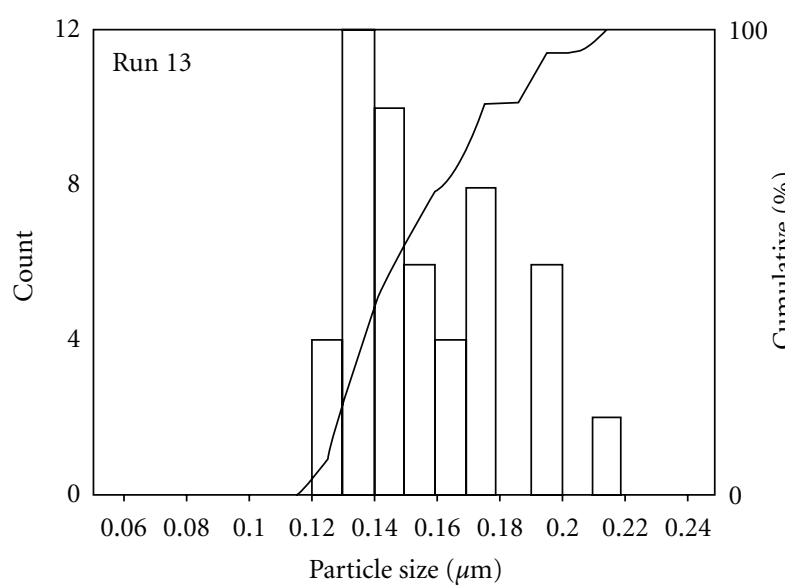

(e)

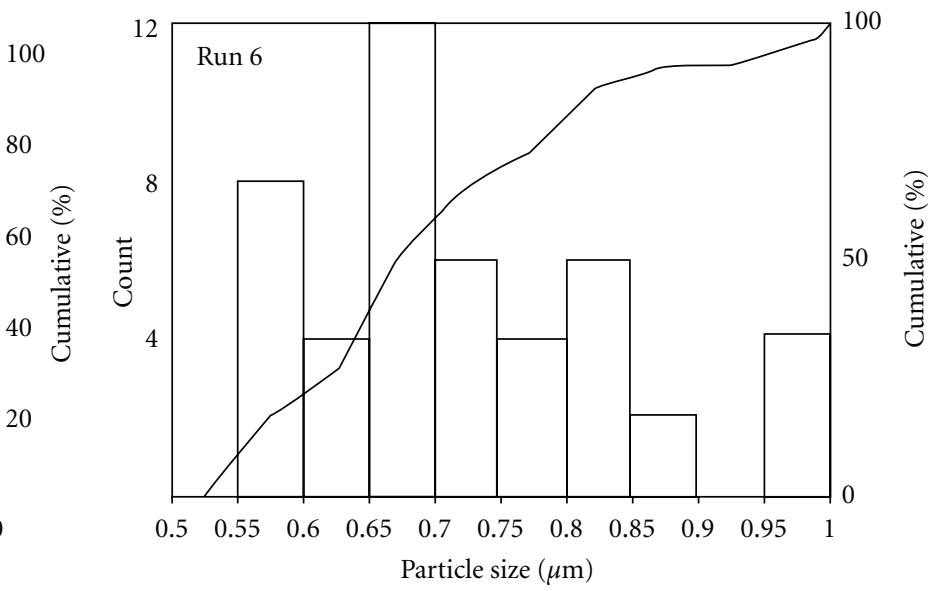

(d)

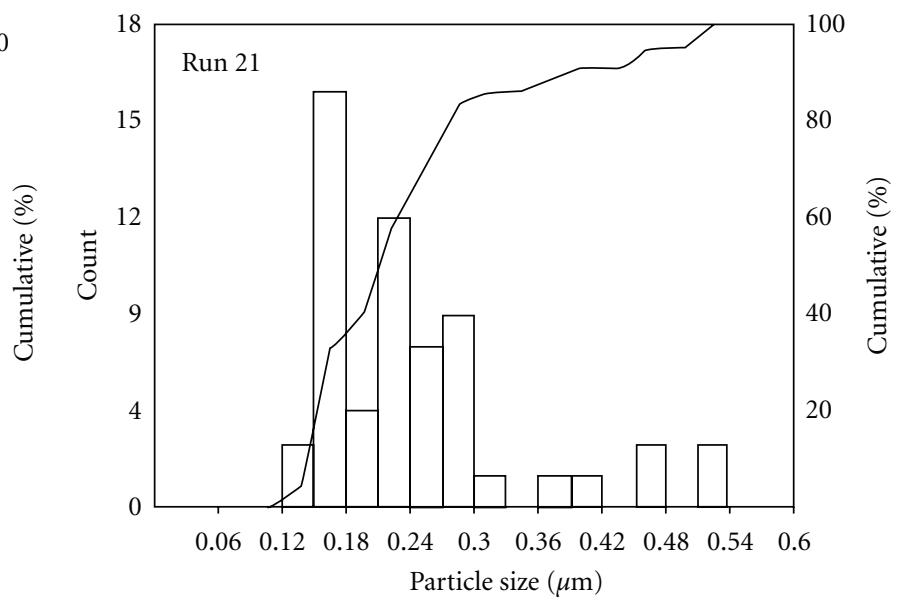

(f)

FIGURe 5: Particle size distribution (PSD) of paracetamol particles at different conditions.

major effect on the average particle size $(P$ value $<0.05)$. Increasing temperature from 273 to $323 \mathrm{~K}$ resulted in decreasing the average particle size as illustrated in the Figure 7(c). This phenomenon could explain that, in the postexpansion chamber and after the tip of nozzle, the flow expands further in a supersonic free jet, where the most of the pressure drop takes place. The temperature and pressure reduction can lead to solvent condensation. Condensation is starting from a point which usually called the Wilsonpoint. From there on, liquid solvent droplets exist besides the continuous vapour phase [23]. In the condensate phase, paracetamol has a greater chance to collide with each other, 


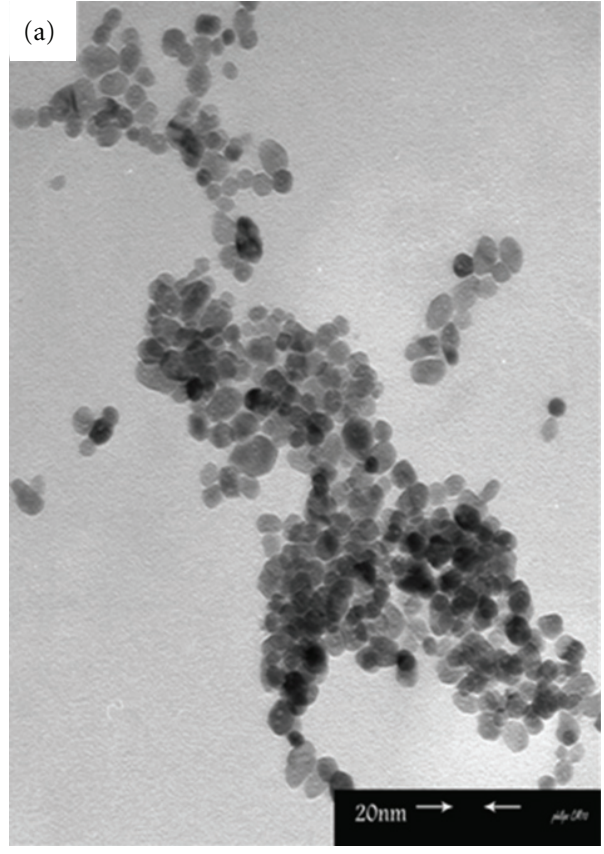

(a)

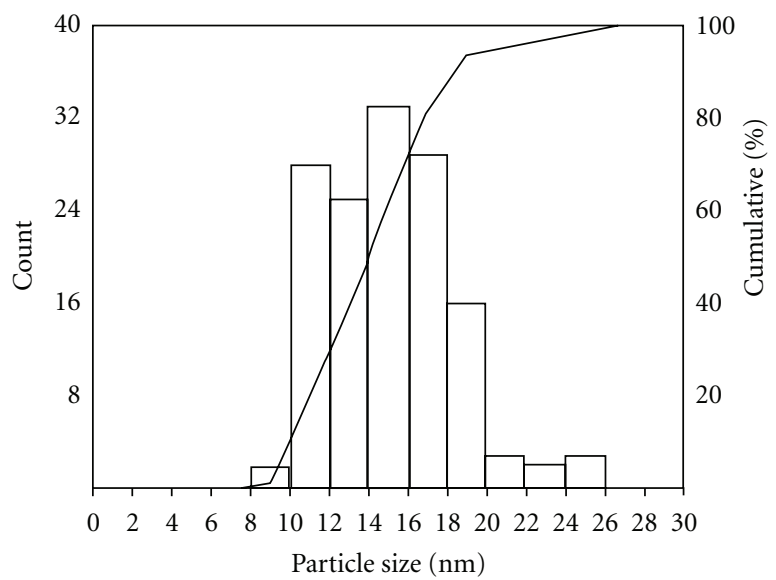

(b)

Figure 6: (a) The TEM images of processed paracetamol particles $\left(T_{\text {Extraction }}=333 \mathrm{~K}, P_{\text {Extraction }}=14 \mathrm{MPa}, T_{\text {Preexpansion }}=383 \mathrm{~K}, T_{\text {Postexpansion }}=\right.$ $298 \mathrm{~K}$, Spray distance $=50 \mathrm{~mm}$ ). (b) Particle size distribution of paracetamol particles (Mean particle size was $15.2 \mathrm{~nm}$ ).

agglomerating to form larger particles. Coagulation and agglomeration are the main reasons for producing larger particles in the RESS process which depends on the rate of successful collision and coalescence. It could be speculated that increasing the postexpansion temperature decreases the volume fraction of condensate phase and can decrease agglomeration and consequently decrease the average particles size. However, Reverchon et al. [19], Alessi et al. [24], and Liu and Nagahama [20] have found decreasing postexpansion temperature leads to decrease in particle size for salicylic acid, steroid drugs, and naphthalene, respectively. These authors reported that decreasing the postexpansion temperature leads to decrease in the solubility of solid in $\mathrm{CO}_{2}$ during expansion and increases the supersaturation; consequently the particle size of solid decreased [16]. Therefore, for better understanding the effect of postexpansion temperature on the particle size, the effect of hydrodynamic conditions in postexpansion unit as well as the nature of solute-solvent system must be considered.

3.2.4. Effect of Extraction Pressure. It can be seen from Table 3 that the extraction pressure has significant effect on the average particles size $(P$ value $<0.05)$. Figure $7(d)$ shows the effect of extraction pressure on average particle size. As depicted in Figure 7(d), increasing extraction pressure from 10 to $16.5 \mathrm{MPa}$ resulted in increasing the particles size. However, the trend was reversed when the extraction pressure increased from 16.5 to $18 \mathrm{MPa}$. The extraction pressure affected the particle size by the following four aspects. Firstly, the concentration of solution was increased by increasing the extraction pressure $[14,15]$; therefore, according to the classical nucleation theory, higher concentration of solution made a decrease of particle size. Secondly, a higher preexpansion pressure led to higher mass flow rates of the solution (it should be to state that in our experiments, the preexpansion pressure was kept equal to the extraction pressure). Consequently, higher mass flow rates of the solution reduced the residence time in the expansion chamber, which was the particle coagulation growth time. Both phenomena were responsible for the decrease of particle size. Thirdly, the higher extraction pressure caused the higher concentration of solution and resulted in the higher particle number concentration. This led to more frequently coagulation among particles and subsequently increased the size of particles. Fourthly, the increased concentration of solution made occurrence of nucleation earlier (entrance of the nozzle) and increased the time of particle growth inside the nozzle. These third and fourth phenomena increased the size of particles. It seems that below the extraction pressure of 16.5 $\mathrm{MPa}$, the two last effects are dominated and resulted in an increasing particle size by increasing extraction pressure, and for upper pressure than $16.5 \mathrm{MPa}$, the two first effects are dominated and caused decreasing particles size by increasing the extraction pressure $[19,22,25]$.

3.3. The Interaction between the Variables. The two- and three-dimensional response surface plots are the graphical representations of the regression equation. These plots were presented in Figures 8-13. These types of plots showed effects of two factors on the response at a time. In all the presented figures, the other factor was kept at level zero. 


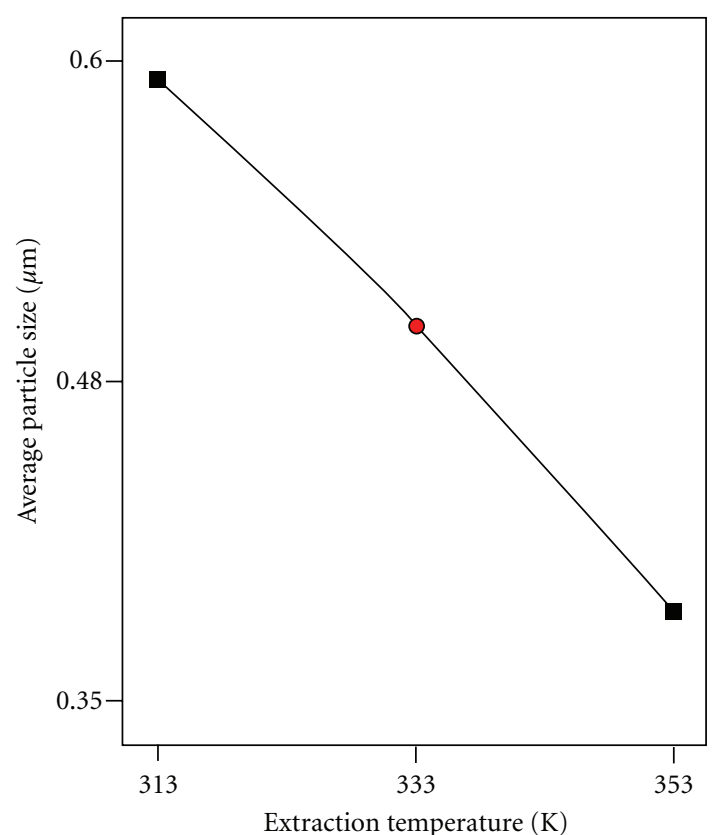

(a)

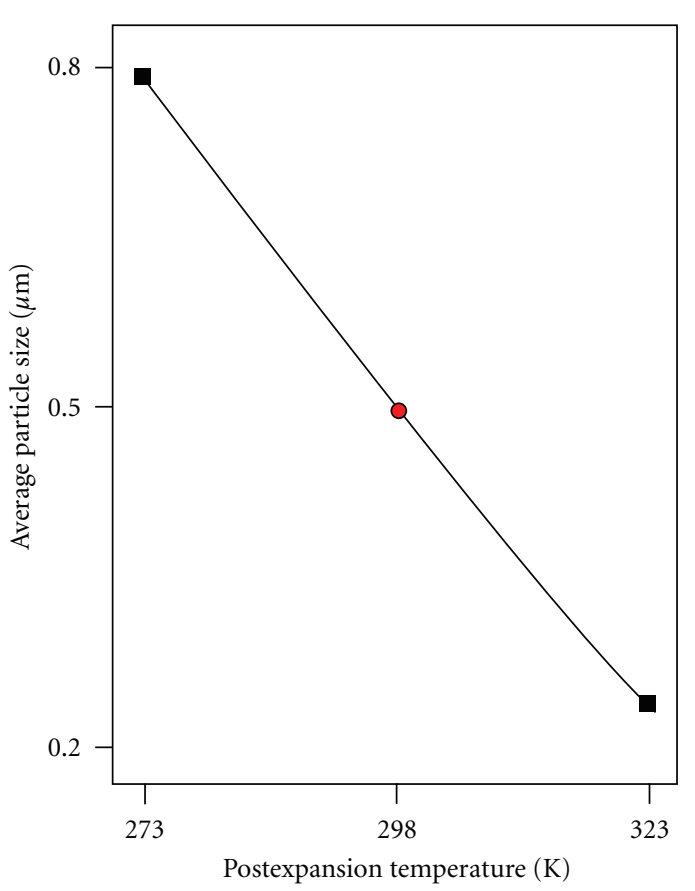

(c)

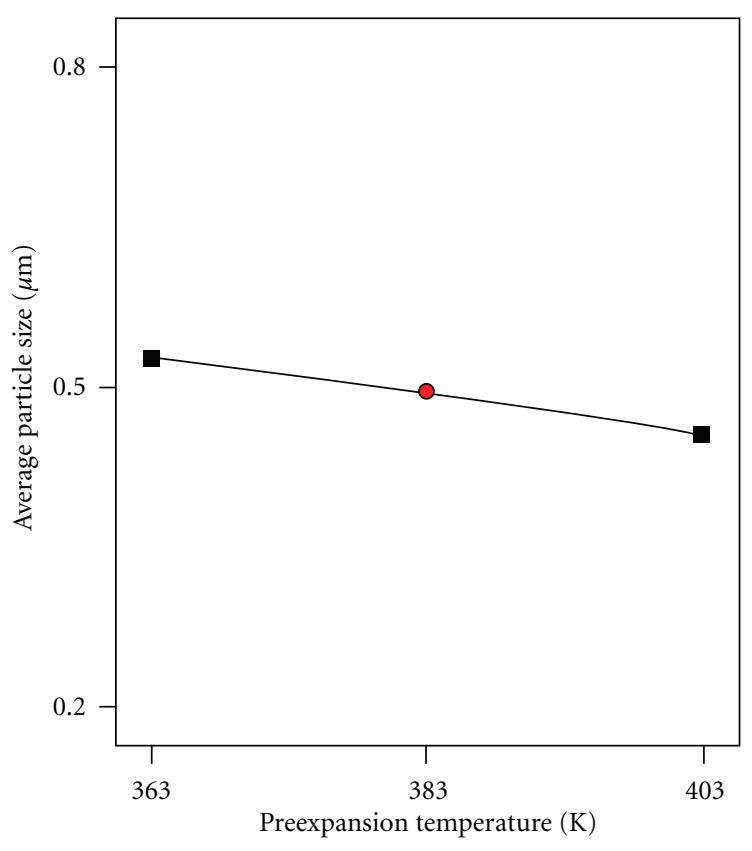

(b)

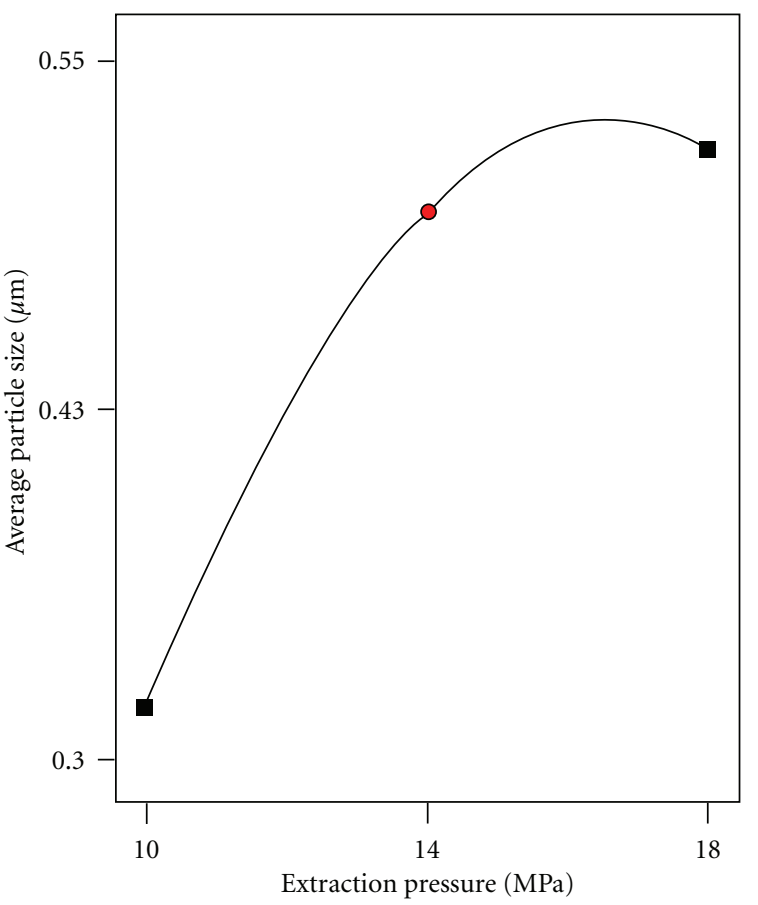

(d)

FIGURE 7: The curve showing the effect of one factor: extraction temperature (a), preexpansion temperature (b), postexpansion temperature (c), and extraction pressure (d), on the average particle size of paracetamol.

Figure 8 represents the effects of extraction temperature and extraction pressure on the average particle size. A decrease in average particle size was observed with increase of extraction temperature and decrease of extraction pressure.

Figure 9 shows the effect of extraction temperature and preexpansion temperature on the average particles size. Increasing extraction temperature and preexpansion temperature led to decrease on average particles size. The interaction between extraction temperature and postexpansion temperature was given in Figure 10. The average particle size increased with decreasing extraction temperature and postexpansion temperature.

Figure 11 represents the effects of preexpansion temperature and extraction pressure on the average particles size. 


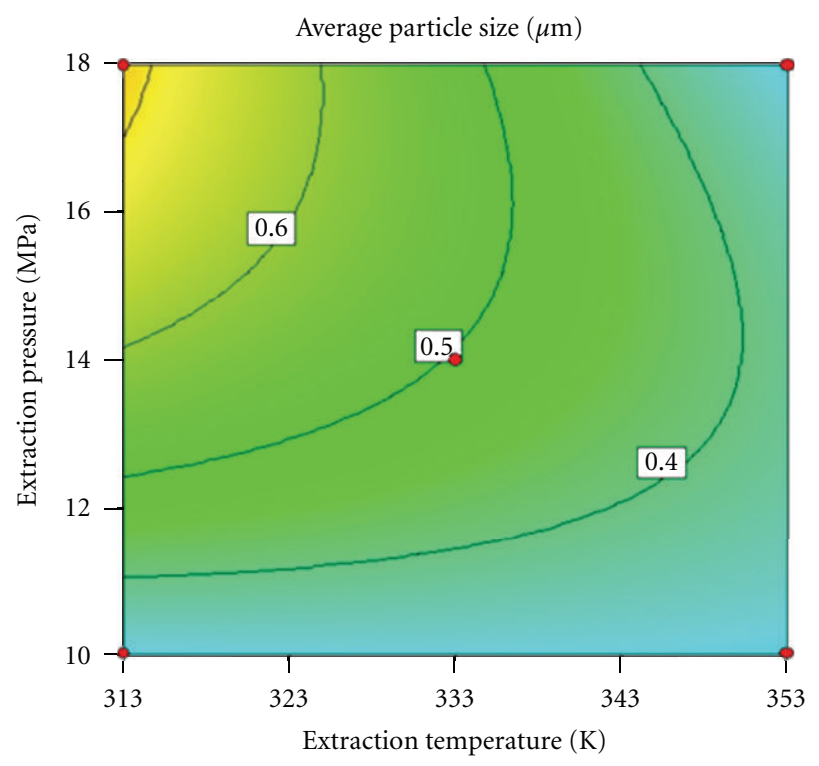

(a)

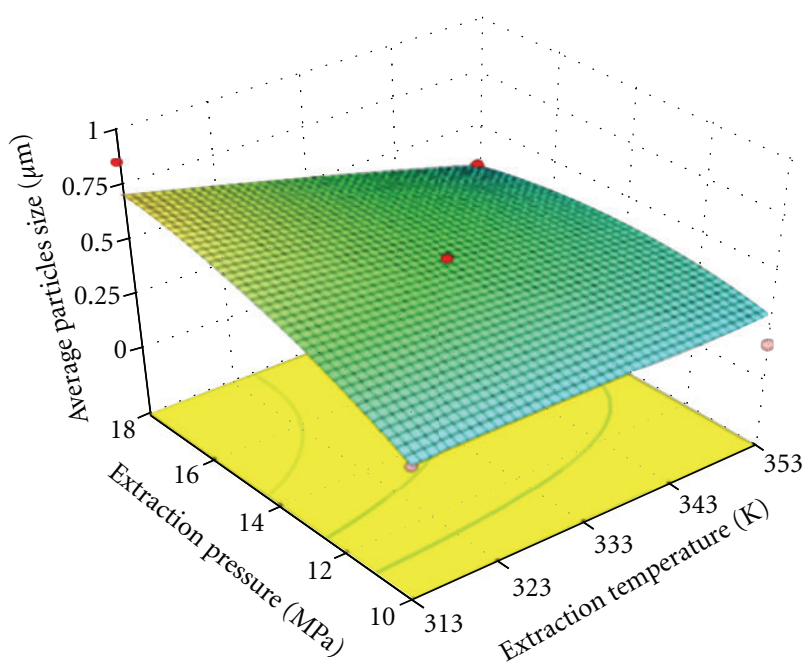

(b)

FIgURE 8: The effects of extraction temperature and extraction pressure on the average particle size of paracetamol: (a) 2D and (b) 3D plot.

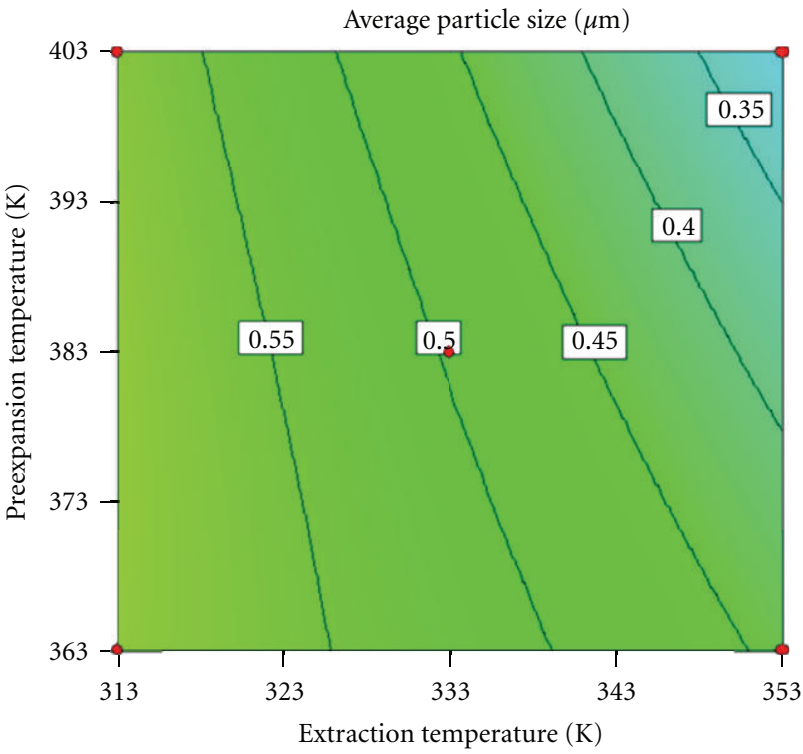

(a)

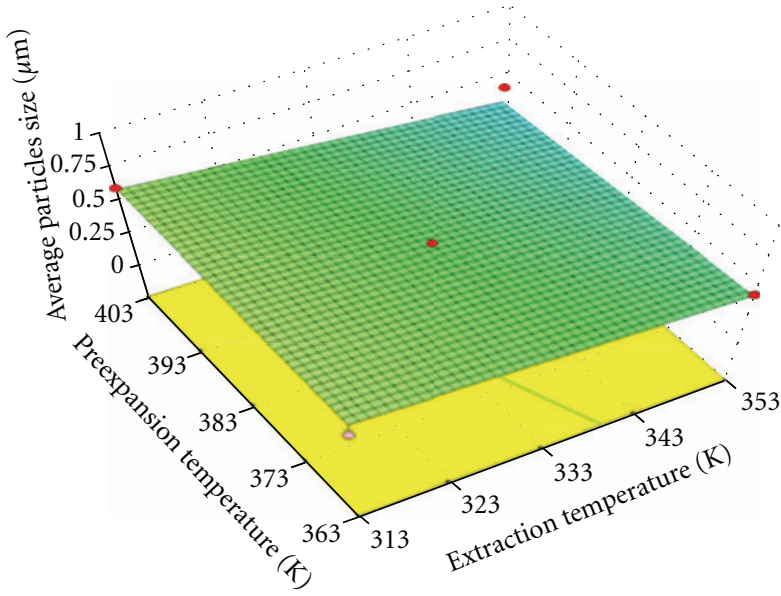

(b)

FIGURE 9: The effects of extraction temperature and preextraction temperature on the average particle size of paracetamol: (a) 2D and (b) 3 p plots.

An increase in average particles size was observed with the decrease of preexpansion temperature from 403 to $363 \mathrm{~K}$ and an increase of extraction pressure from 10 to $18 \mathrm{MPa}$.

The effect of extraction pressure and postexpansion temperature was given in Figure 12. Increasing extraction pressure and decreasing postexpansion temperature directed to increase on particles size.

Figure 13 shows the effect of preexpansion temperature and postexpansion temperature on the average particle size.
As could be seen from this figure, decreasing in preexpansion temperature and postexpansion temperature caused to increase to average particle size.

3.4. Validation of the Model. The optimum values of the variables were determined in order to obtain the smallest particle size by the Design-Expert software. These values were extraction temperature, $347 \mathrm{~K}$; extraction pressure, $12 \mathrm{MPa}$; preexpansion temperature, $403 \mathrm{~K}$; postexpansion temperature, 


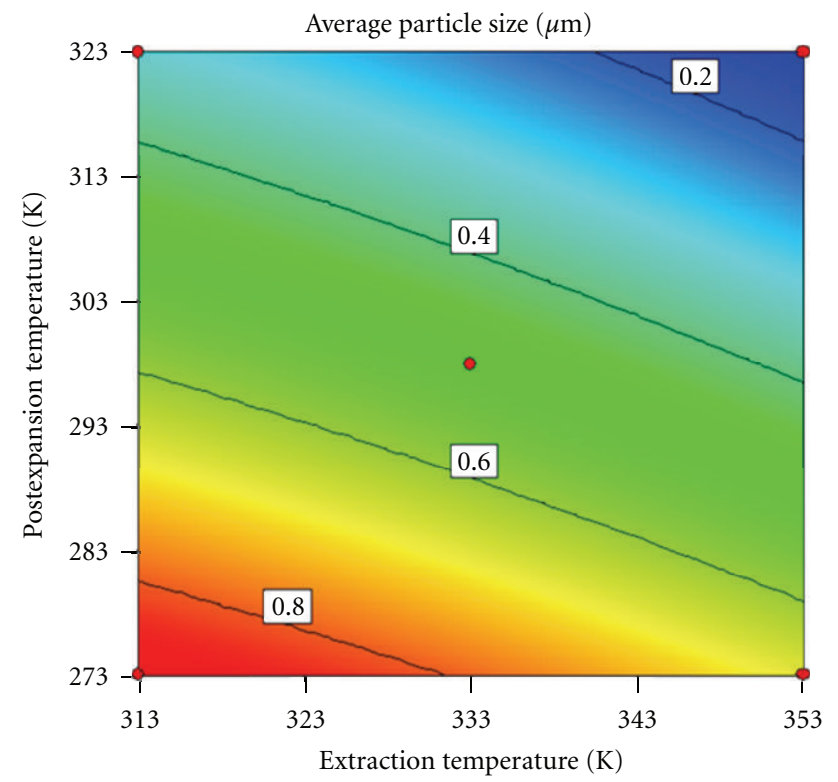

(a)

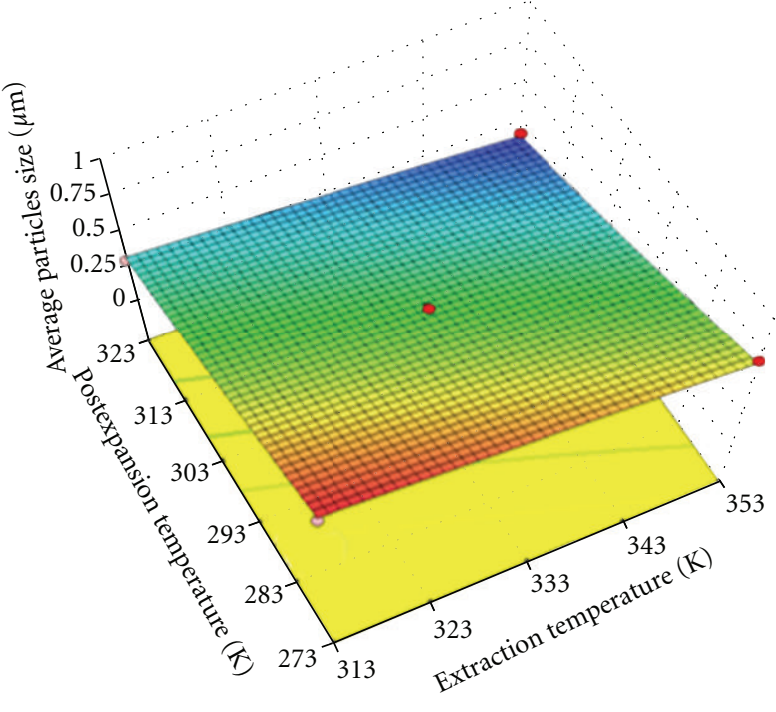

(b)

FIGURE 10: The effects of extraction temperature and post-extraction temperature on the average particle size of paracetamol: (a) 2D and (b) 3D plots.

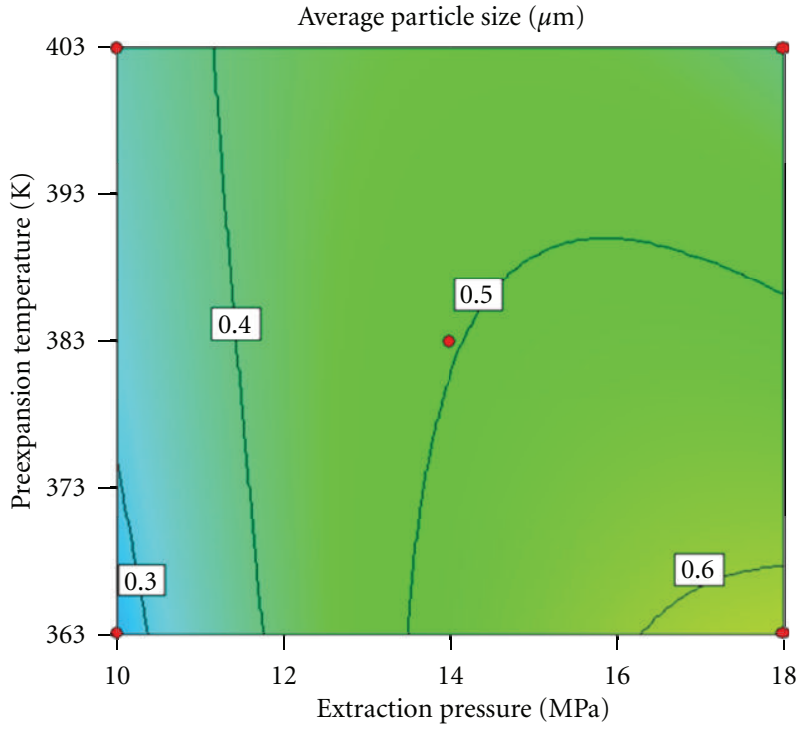

(a)

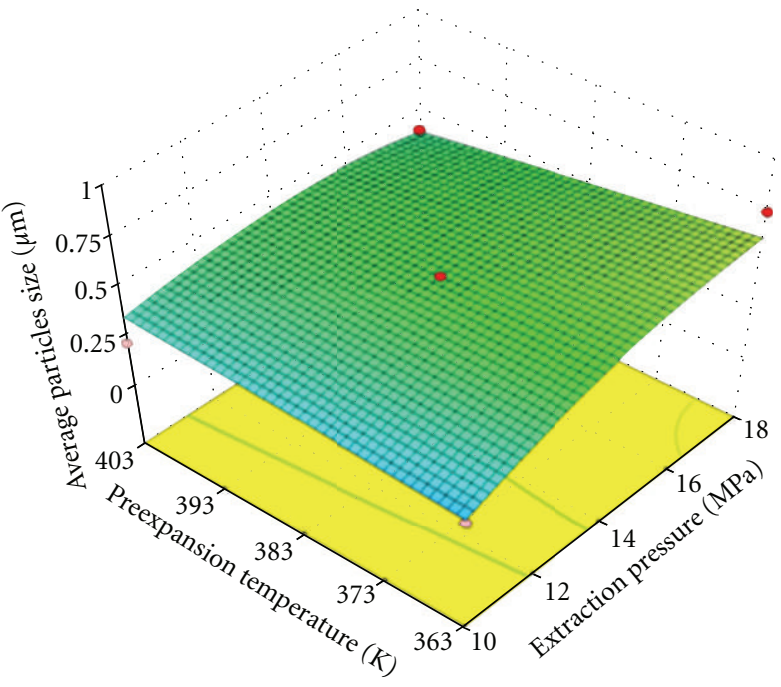

(b)

FIGURE 11: The effects of extraction pressure and preexpansion temperature and on the average particle size of paracetamol: (a) 2D and (b) 3 plots.

$322 \mathrm{~K}$; and the response (average particle size), $0.117 \mu \mathrm{m}$. In order to validate the adequacy of the model equations, a verification experiment was carried out under the optimal conditions. A mean value of $0.129 \mu \mathrm{m}$, obtained from real experiments, the experimental $(0.129 \mu \mathrm{m})$, and calculated $(0.117 \mu \mathrm{m})$ response value were closed to each other and demonstrated the validation of the Box-Behnken model.
3.5. Structure Analysis of Processed Paracetamol Particles. The LC-Mass results were shown in Figure 14. The LC-MS chromatogram peaks of original and RESS processed particles were at 3.983 and $3.265 \mathrm{~min}$, respectively (Figures 14(a) and 14(b)). The molecular mass was determined to be 151.1 g/mol. (In Figure 14, peaks at 152.1 and 174.1 indicate the mass of a molecular of paracetamol pluse 1 and pluse 23 


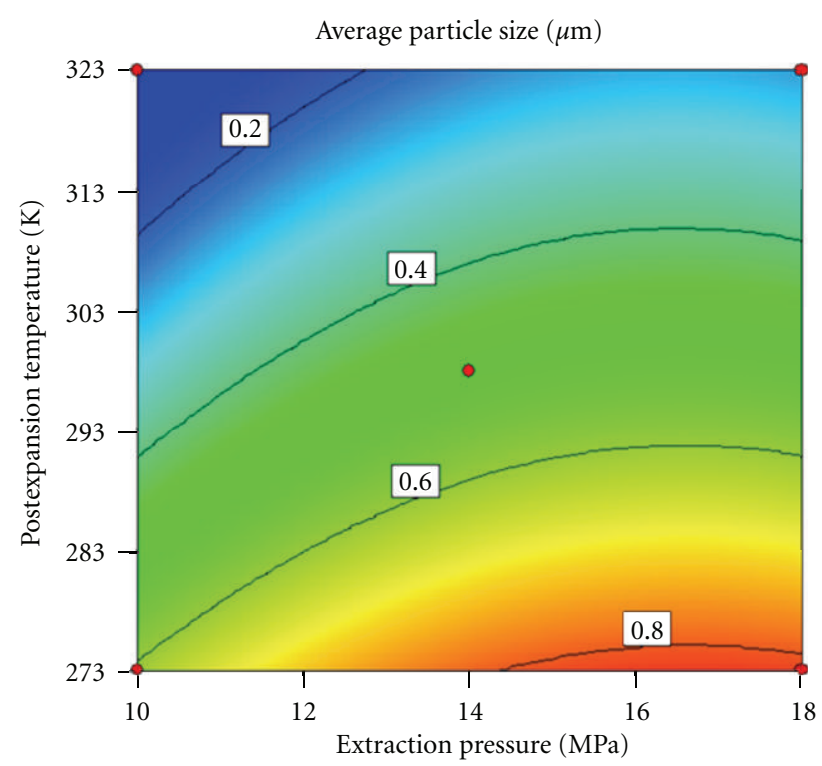

(a)

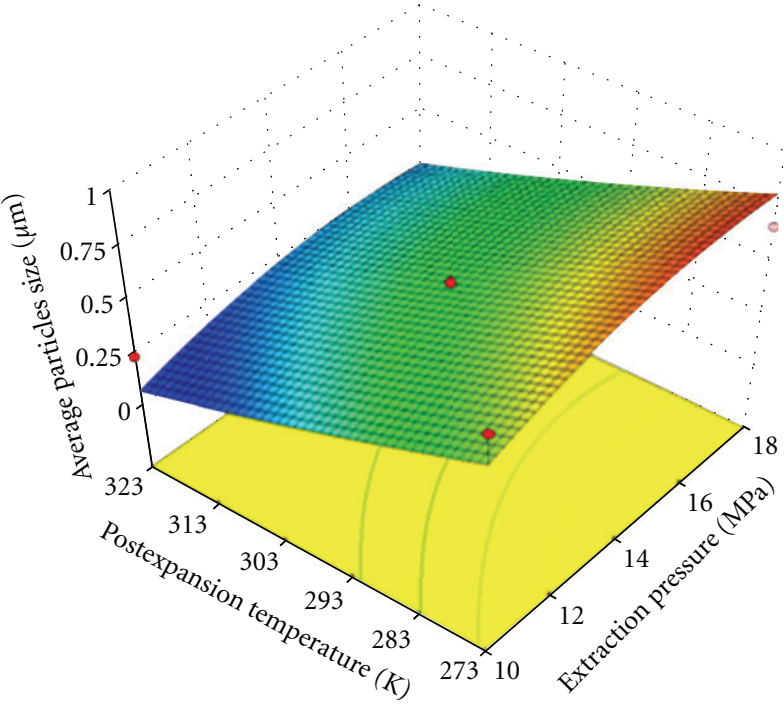

(b)

FIGURE 12: The effects of extraction pressure and postexpansion temperature and on the average particle size of paracetamol: (a) 2D and (b) 3 D plots.

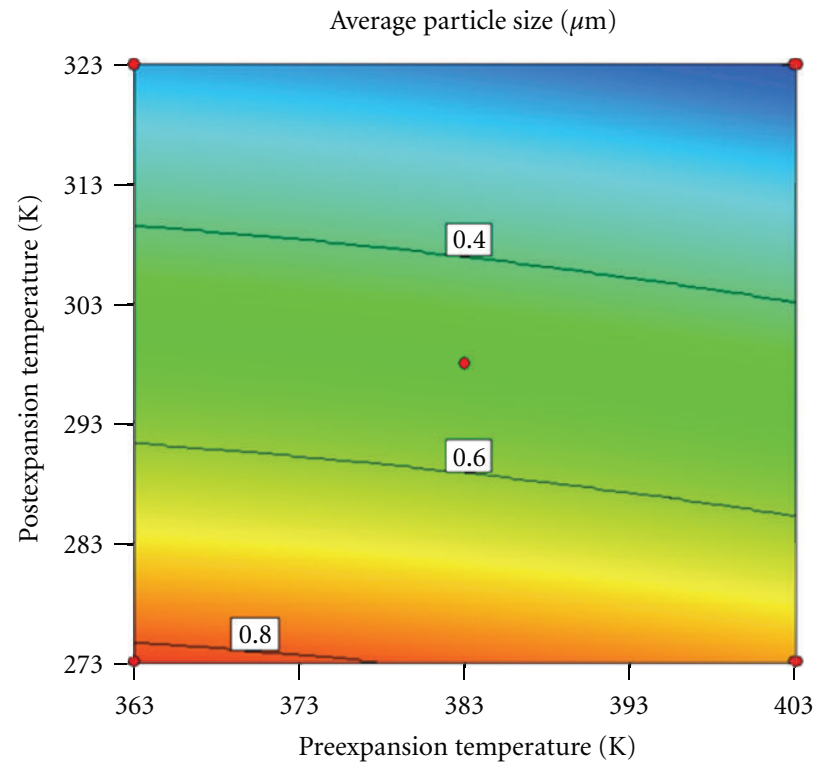

(a)

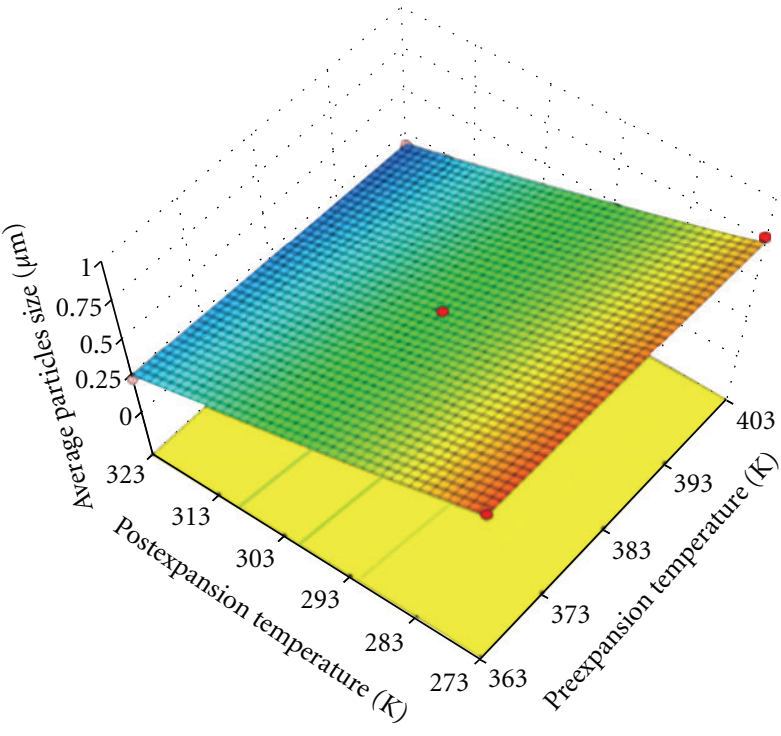

(b)

FIGURE 13: The effects of preexpansion temperature and postexpansion temperature on the average particle size of paracetamol: (a) 2D and (b) $3 \mathrm{D}$ plots.

(hydrogen adduct and sodium adduct), resp.) Therefore, as exposed in Figure 14, no change was observed in the structure of processed paracetamol which indicated that the aforementioned parameters did not affect the structure of paracetamol and RESS process can be considered as a safe process for making ultrafine particles of paracetamol.

\section{Conclusion}

In this study, micronization of paracetamol was carried out by RESS process. The effects of process parameters such as extraction temperature $\left(x_{1}\right)$, extraction pressure $\left(x_{2}\right)$, preexpansion temperature $\left(x_{3}\right)$, and postexpansion 


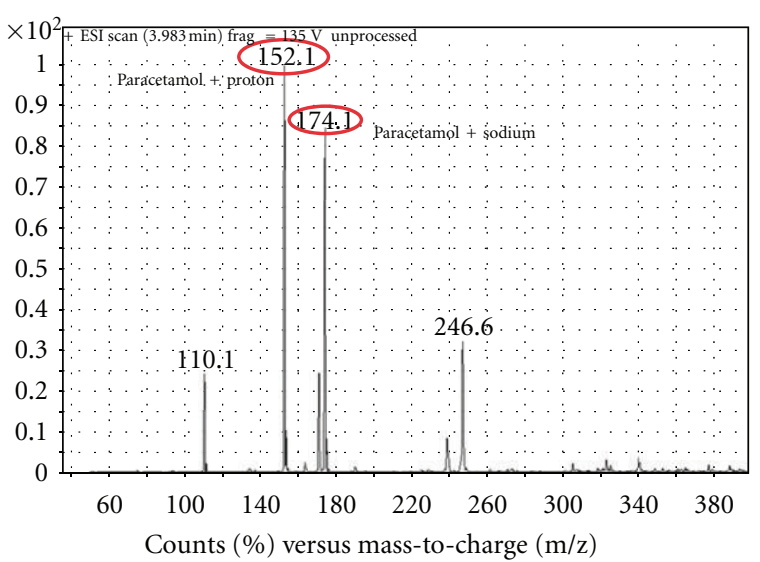

(a)

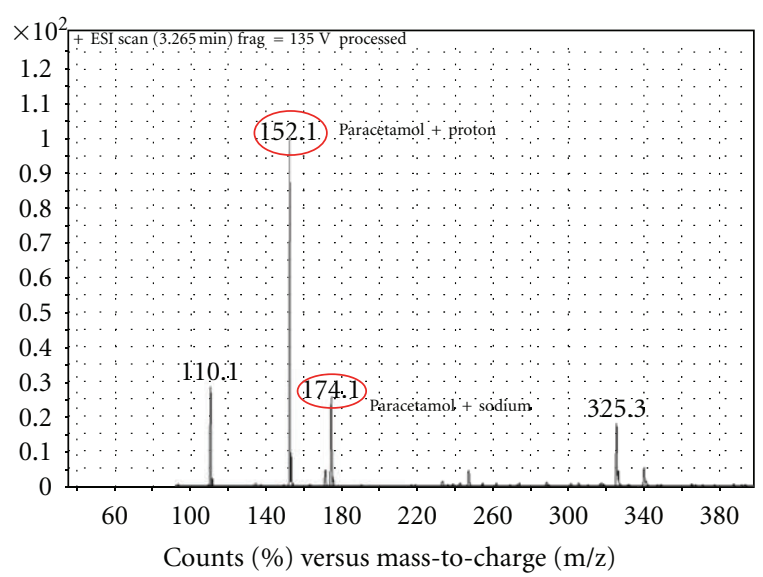

(b)

FIGURE 14: LC-MS analysis of paracetamol. (a) Unprocessed (mass spectrum) and (b) RESS processed (mass spectrum) $\left(T_{\text {Extraction }}=353 \mathrm{~K}\right.$, $P_{\text {Extraction }}=18 \mathrm{MPa}, T_{\text {Preexpansion }}=403 \mathrm{~K}, T_{\text {Postexpansion }}=323 \mathrm{~K}$, Spray distance $\left.=50 \mathrm{~mm}\right)$.

temperature $\left(x_{4}\right)$ on the particles size of paracetamol were determined using response surface methodology. Our results depict that the process parameters have a significant effect on the particles size and morphology. The average particle size of paracetamol particles was reduced from $20.8 \mu \mathrm{m}$ to $0.46 \mu \mathrm{m}$ by changing process parameters. The dependent variable and independent variable were related by the following secondorder polynomial equation:

$$
\begin{aligned}
Y= & 0.5-0.1 x_{1}+0.099 x_{2}-0.035 x_{3}-0.28 x_{4} \\
& -0.1 x_{1} x_{2}-0.029 x_{1} x_{3}+0.007 x_{1} x_{4}-0.077 x_{2} x_{3} \\
& -0.0045 x_{2} x_{4}+0.0015 x_{3} x_{4}-0.00829 x_{1}^{2} \\
& -0.078 x_{2}^{2}-0.00654 x_{3}^{2}+0.018 x_{4}^{2} .
\end{aligned}
$$

Box-Behnken design was successfully applied for optimization of particle size design parameters by RESS. The optimum values of the variables (extraction temperature, $347 \mathrm{k}$; extraction pressure, $12 \mathrm{MPa}$; preexpansion temperature, $403 \mathrm{~K}$; and postexpansion temperature, $322 \mathrm{~K}$ ) were determined in order to obtain the smallest average particle size. The particles size of paracetamol decreased with the increase of extraction temperature and postexpansion temperature. Moreover, the particles size of paracetamol increased by increasing extraction pressure at first but the trend was reversed when the extraction pressure reached at a certain value $(16.5 \mathrm{MPa})$. However, the preexpansion temperature has very small (insignificant) effect on the particle size. Precipitated paracetamol was analyzed by LCMS. The results showed that RESS process did not change the chemical nature of the materials. It is concluded that particle size of paracetamol can be decreased to nanoscale in a supercritical fluid with RESS process.

\section{Acknowledgment}

The authors would like to thank Mr. R. Ramezani for his support in doing Box-Behnken experimental design.

\section{References}

[1] I. De Marco and E. Reverchon, "Nanostructured cellulose acetate filaments produced by supercritical antisolvent precipitation," Journal of Supercritical Fluids, vol. 55, no. 3, pp. 10951103, 2011.

[2] E. Reverchon and R. Adami, "Nanomaterials and supercritical fluids," Journal of Supercritical Fluids, vol. 37, no. 1, pp. 1-22, 2006.

[3] R. Vasita and D. S. Katti, "Nanofibers and their applications in tissue engineering," International Journal of Nanomedicine, vol. 1, no. 1, pp. 15-30, 2006.

[4] M. Goldberg, R. Langer, and X. Jia, "Nanostructured materials for applications in drug delivery and tissue engineering," Journal of Biomaterials Science, Polymer Edition, vol. 18, no. 3, pp. 241-268, 2007.

[5] Y. Zhang, T. L. Chwee, S. Ramakrishna, and Z. M. Huang, "Recent development of polymer nanofibers for biomedical and biotechnological applications," Journal of Materials Science: Materials in Medicine, vol. 16, no. 10, pp. 933-946, 2005.

[6] Q. P. Pham, U. Sharma, and A. G. Mikos, "Electrospinning of polymeric nanofibers for tissue engineering applications: a review," Tissue Engineering, vol. 12, no. 5, pp. 1197-1211, 2006.

[7] R. Z. Valiev, M. J. Zehetbauer, Y. Estrin et al., "The innovation potential of bulk nanostructured materials," Advanced Engineering Materials, vol. 9, no. 7, pp. 527-533, 2007.

[8] C. Atila, N. Yildiz, and A. Çalimli, "Particle size design of digitoxin in supercritical fluids," Journal of Supercritical Fluids, vol. 51, no. 3, pp. 404-411, 2010.

[9] J. Jung and M. Perrut, "Particle design using supercritical fluids: literature and patent survey," Journal of Supercritical Fluids, vol. 20, no. 3, pp. 179-219, 2001.

[10] T. Pérez-Ruiz, C. Martínez-Lozano, V. Tomás, and R. Galera, "Migration behaviour and separation of acetaminophen and p-aminophenol in capillary zone electrophoresis: analysis of drugs based on acetaminophen," Journal of Pharmaceutical and Biomedical Analysis, vol. 38, no. 1, pp. 87-93, 2005.

[11] M. Türk and R. Lietzow, "Formation and stabilization of submicron particles via rapid expansion processes," Journal of Supercritical Fluids, vol. 45, no. 3, pp. 346-355, 2008. 
[12] M. Türk and D. Bolten, "Formation of submicron poorly water-soluble drugs by rapid expansion of supercritical solution (RESS): results for naproxen," Journal of Supercritical Fluids, vol. 55, no. 2, pp. 778-785, 2010.

[13] Y. P. Sun, "Supercritical fluid technology in materials science and engineering syntheses, properties, and application," in Understanding the RESS Process, M. Weber and M. Thies, Eds., pp. 387-437, Marcel Dekker, Basel, Switzerland, 2002.

[14] S. Bristow, B. Y. Shekunov, and P. York, "Solubility analysis of drug compounds in supercritical carbon dioxide using static and dynamic extraction systems," Industrial and Engineering Chemistry Research, vol. 40, no. 7, pp. 1732-1739, 2001.

[15] J. Karimi Sabet, C. Ghotbi, F. Dorkoosh, and A. Striolo, "Solubilities of acetaminophen in supercritical carbon dioxide with and without menthol cosolvent: measurement and correlation," Scientia Iranica, Transactions C. In press.

[16] N. Yildiz, Ş. Tuna, O. Döker, and A. Çalimli, "Micronization of salicylic acid and taxol (paclitaxel) by rapid expansion of supercritical fluids (RESS)," Journal of Supercritical Fluids, vol. 41, no. 3, pp. 440-451, 2007.

[17] M. Türk, "Influence of thermodynamic behaviour and solute properties on homogeneous nucleation in supercritical solutions," Journal of Supercritical Fluids, vol. 18, no. 3, pp. 169$184,2000$.

[18] Z. Huang, G. B. Sun, Y. C. Chiew, and S. Kawi, "Formation of ultrafine aspirin particles through rapid expansion of supercritical solutions (RESS)," Powder Technology, vol. 160, no. 2, pp. 127-134, 2005.

[19] E. Reverchon, G. Donsi, and D. Gorgoglione, "Salicylic acid solubilization in supercritical $\mathrm{CO}_{2}$ and its micronization by RESS," The Journal of Supercritical Fluids, vol. 6, no. 4, pp. 241248, 1993.

[20] G. T. Liu and K. Nagahama, "Application of rapid expansion of supercritical solutions in the crystallization separation," Industrial and Engineering Chemistry Research, vol. 35, no. 12, pp. 4626-4634, 1996.

[21] B. Helfgen, M. Türk, and K. Schaber, "Theoretical and experimental investigations of the micronization of organic solids by rapid expansion of supercritical solutions," Powder Technology, vol. 110, no. 1-2, pp. 22-28, 2000.

[22] J. Wang, J. Chen, and Y. Yang, "Micronization of titanocene dichloride by rapid expansion of supercritical solution and its ethylene polymerization," Journal of Supercritical Fluids, vol. 33, no. 2, pp. 159-172, 2005.

[23] B. Helfgen, M. Türk, and K. Schaber, "Hydrodynamic and aerosol modelling of the rapid expansion of supercritical solutions (RESS-process)," Journal of Supercritical Fluids, vol. 26, no. 3, pp. 225-242, 2003.

[24] P. Alessi, A. Cortesi, I. Kikic, N. R. Foster, S. J. Macnaughton, and I. Colombo, "Particle production of steroid drugs using supercritical fluid processing," Industrial and Engineering Chemistry Research, vol. 35, no. 12, pp. 4718-4726, 1996.

[25] P. A. Charpentier, M. Jia, and R. A. Lucky, "Study of the RESS process for producing beclomethasone-17,21-dipropionate particles suitable for pulmonary delivery," AAPS PharmSciTech, vol. 9, no. 1, pp. 39-46, 2008. 

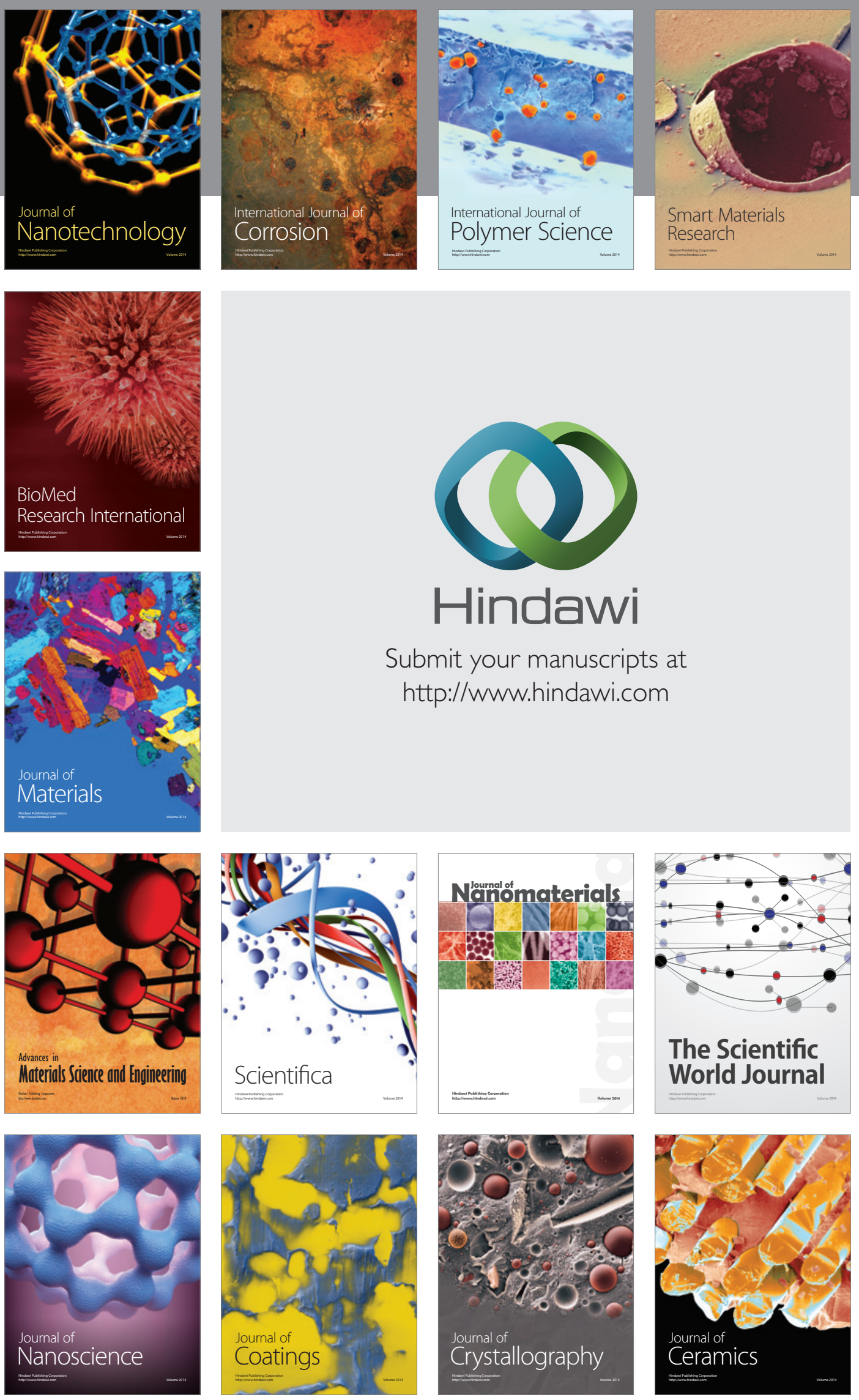

The Scientific World Journal

Submit your manuscripts at

http://www.hindawi.com

\section{World Journal}

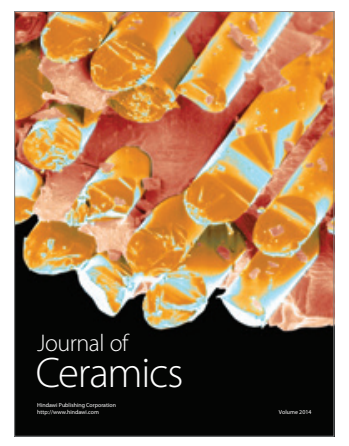

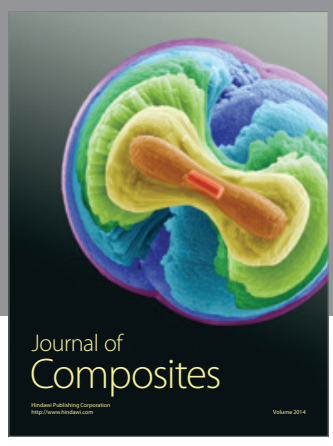
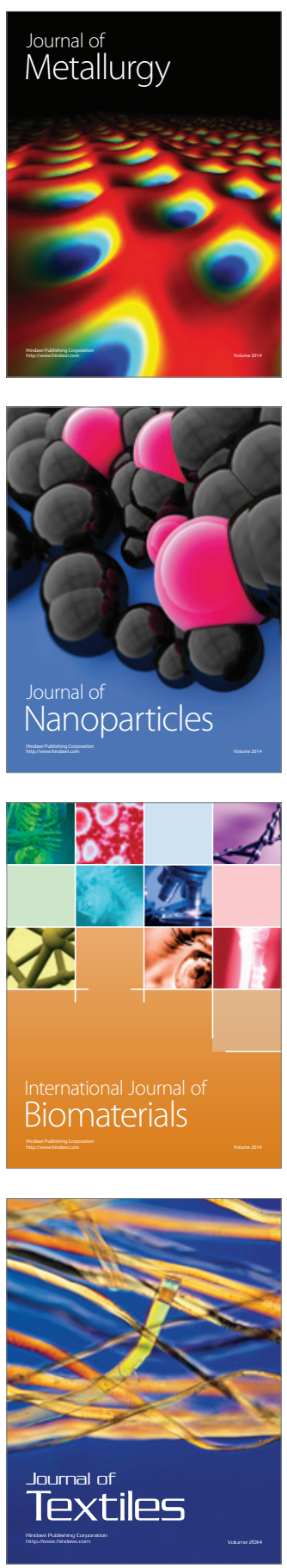